\title{
Inventário de fitólitos da floresta ombrófila mista: subsídios para estudos paleoambientais
}

\author{
The phytolith inventory of Araucaria forest: subsidies for \\ paleoenvironmental studies
}

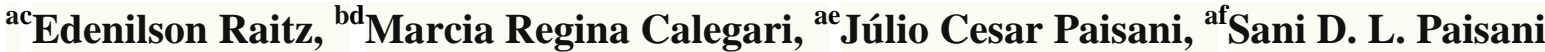

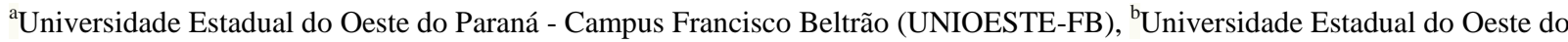
Paraná - Campus Marechal Cândido Rondon (UNIOESTE-MCR)

cedenilsonraitz@hotmail.com, ${ }^{\mathrm{d}}$ marciareg_calegari@hotmail.com, ${ }^{\mathrm{e}}$ juliopaisani@hotmail.com, ${ }^{\mathrm{f}}$ sanidaniela@ hotmail.com

\begin{abstract}
Resumo
Em vários estudos de microfósseis as análises polínicas e isotópicas, entre outras técnicas, são utilizadas como meios para investigar o comportamento climático e suas implicações nos paleoambientes. A essas técnicas de investigação, soma-se a análise fitolítica, utilizada para complementar os estudos do Quaternário. Fitólitos são corpos de sílica amorfa $\left(\mathrm{SiO}_{2} \cdot \mathrm{nH}_{2} 0\right)$ produzidos por plantas que, após a morte de suas produtoras, podem ser incorporados ao solo, onde permanecem por longos períodos de tempo. Para realização de uma interpretação consistente, há necessidade de coleções de referência para comparações entre os fitólitos de plantas vivas com aqueles incorporados aos solos. O objetivo deste trabalho foi elaborar uma coleção de referência de fitólitos de plantas modernas de um fragmento representativo da Floresta Ombrófila Mista (FOM), na região Sudoeste do Paraná. Foi realizada a extração de fitólitos em 42 espécies pertencentes a 28 famílias da FOM. Em apenas duas espécies não foram observados fitólitos, R.gardneriana e A. angustifolia. Os resultados indicaram que as espécies selecionadas tiveram produção elevada de fitólitos e os morfotipos identificados podem permitir interpretações paleoambientais mais precisas. Não foi observada afinidade em termos de produção (quantidade e diversidade) entre os estratos, e nenhum morfotipo novo foi identificado. Ao final deste trabalho conclui-se que é evidente a necessidade de ampliação das coleções de referência da FOM com espécies coletadas em outros locais para investigar a existência de variação na produção de fitólitos intra e entre famílias.
\end{abstract}

Palavras-Chave: Opala biogênica; Coleção de referência; Reconstrução paleoambiental.

\begin{abstract}
In several studies of microfossils, pollen and isotopic analysis, among other techniques, are used to investigate the climatic behavior and its palaeoenvironmental implications. To this group of investigative techniques phytolith analysis can be added, in order to complement studies of the Quaternary. Phytoliths are bodies of amorphous silica $\left(\mathrm{SiO}_{2} \cdot \mathrm{nH}_{2} \mathrm{O}\right)$ produced by plants that, after the death of their producers, can be incorporated into the soil, where they may remain for long periods of time. For performing a consistent interpretation, reference collections are needed for comparisons between phytoliths of fresh plants with phytoliths incorporated into the soil. The aim of this study was to develop a reference collection of phytoliths of modern plants from a fragment of Araucaria Forest (AF), representative of the Southwest of Paraná State vegetation. The extraction of phytoliths was performed in 42 species belonging to 28 families of AF. In only two species phytoliths have not been observed, the $R$. gardneriana and A. angustifolia. The results indicated that the selected species produce a large amount of phytoliths and the identified morphotypes may allow more accurate palaeoenvironmental interpretations. No affinity in production (quantity and diversity) was observed between strata and no new morphotype was identified. At the end of this work we can conclude that it is necessary to expand the collections of reference of the Araucaria Forest, using specimens collected from other sites to investigate the existence of variations in the production of phytoliths within and among families.
\end{abstract}

Keywords: biogenic opal; Reference collection; palaeoenvironmental reconstruction.

\section{Introdução}

Fitólitos, termo que deriva do grego "phyto=planta" e "lithos=pedra"; significa "pedra produzida por plantas". E são biomineralizações formadas a partir da deposição da sílica amorfa hidratada não cristalina dentro e entre as células de diferentes tecidos vegetais, ao longo do ciclo vegetativo de muitas espécies de plantas (Rovner 1971, Piperno 2006) e possuem 
dimensões microscópicas, entre 2 e $50 \mu \mathrm{m}$ (Piperno 2006).

As coleções de referências de fitólitos representam uma maneira de organizar os dados sobre sua produção (quantidade e diversidade) por uma dada planta ou fitofisionomia (Kealhofer \& Piperno 1998). A análise de fitólitos é uma frente de pesquisa, cuja evolução está relacionada às suas aplicações e às suas potencialidades em estudos de botânica, etnobotânica, arqueologia, reconstrução paleoambiental, tendências de evolução pedogenética e evolução da paisagem (Twiss et al. 1969, Rovner 1971, Mulholland \& Rapp Jr. 1992, Fredlund \& Tieszen 1994, Barboni et al. 1999, Piperno 1988, 2006, Calegari et al. 2013, Coe et al. 2013).

Conhecer a produção de fitólitos pelas plantas atuais é um meio de minimizar as limitações da análise fitolítica reconhecidas por Rovner (1971) como a multiplicidade (uma planta é produtora de variadas morfologias de fitólitos) e a redundância (um mesmo morfotipo de fitólito é produzido por muitos taxa). Quanto mais espécies, subfamílias e famílias de uma fitofisionomia forem estudadas, mais fitólitos com significado taxonômico (aqueles que permitem identificar a família, gênero ou espécie de planta que o produziu) e ambiental (permitem identificar o ambiente em que as plantas que os produzem se desenvolveram) serão conhecidos (Osterrieth et al. 2008). Para isto, é necessário conhecer os morfotipos produzidos por uma vegetação de representatividade regional, em nível elevado de discriminação entre morfologias fitolíticas (Piperno \& Pearsall 1998, Pearsall et al. 2003, Strömberg et al. 2007, Barboni et al. 2007).

A anáise fitolítica vem sendo usada pela arqueologia desde os anos 70 (Rovner 1971, Piperno 1988) e se encontra bastante desenvolvida em países europeus e norte-americanos. Na América dos Sul destaca-se a Argentina, com os trabalhos pioneiros de Hetty Bertoldi de Pomar, que entre 1969 e 1983, investigou a presença de fitólitos em plantas e os preservados em distintos tipos de depósitos sedimentares (Zucol et al. 2004). No Brasil estes estudos ainda carecem de informações básicas, como aquelas aportadas pelas coleções de referência. Calegari et al. (2013) destacam que os estudos recentes consideram os dados aportados pelo conjunto fitolítico de extrema importância na reconstrução das características das paisagens brasileiras, sobretudo quando se utilizam solos minerais, não hidromórficos, como registro de mudanças ambientais. Nesta linha alguns trabalhos se destacam como os Kondo \& Iwasa (1981), Alexandre et al. (1999), Borba-Roschel et al. (2006), Lepsch \& Paula (2006), Calegari et al. 2013, Coe et al. (2013), Macedo (2014).

Os trabalhos pioneiros de coleções de referências de fitólitos no Brasil foram iniciados na década $50 \mathrm{com}$ Luiz Gouveia Labouriau e colaboradores, com plantas do Bioma Cerrado. Este grupo desenvolveu um conjunto de procedimentos que são empregados atualmente, com poucas variações, para extração de fitólitos de plantas modernas. Nos trabalhos de
Sendulsky \& Labouriau (1966), Cavalcante (1968), Campos \& Labouriau (1969), Silva \& Labouriau (1970), Söndahl \& Labouriau (1970) são apresentados os resultados de extrações de fitólitos realizadas em cerca de 100 espécies de Poaceae e algumas eudicotiledôneas do Cerrado brasileiro. Depois disso, contata-se uma ausência de estudos sobre coleções de referencias de fitólitos no Brasil até os anos 2010, quando as coleções de referência foram retomadas, estudando a produção de fitólitos em um conjunto de plantas representativas de fitofisionomias da Mata Atlântica (Raitz 2012, Cecchect 2012, Felipe 2012, Brustolin 2013 inéditos) e de espécies isoladas de fragmentos de Cerrado no estado do Paraná (Rasbold et al. 2011) subsidiando o crescente uso da análise fitolítica como ferramenta para estudos de gênese de solo, para reconstrução (paleo)ambiental e evolução da paisagem (por exemplo Calegari et al. 2013, Paisani et al. 2013).

De modo geral, coleções de referência de plantas modernas ainda são poucas para as zonas tropicais, quando comparadas as de zonas temperadas do globo. Destacam-se aquelas realizadas a partir dos anos 90, na África (por exemplo, Runge 1999, Barboni et al. 2007), pradarias norte americanas (Twiss 1992), América Central (Piperno 2006) e Noroeste da Austrália (Wallis 2003). Visando a reconstrução de atividades humanas, Kaplan et al. (1992) organizaram uma coleção de referência de fitólitos de grãos de cereais e de espécies não graminóides nativas do Sudoeste da Ásia e da Europa, importante para as pesquisas arqueológicas.

Considerando a importância das coleções de fitólitos extraídos de plantas para subsidiar a correta identificação e construção de paisagens e vegetações pretéritas (Pearsall \& Trimble 1984, Piperno 1988) o presente trabalho apresenta os resultados iniciais de uma pesquisa sobre a produção e morfologias de fitólitos de plantas de um fragmento da Floresta Ombrófila Mista (FOM), no Sudoeste do Paraná.

\section{Material e métodos}

O estudo foi realizado em um fragmento de floresta na região fitogeográfica da Floresta Ombrófila Mista (Fragmento FOM), em Francisco Beltrão no Sudoeste do Estado do Paraná (figura $1 \mathrm{I}$ ). A área esta localizada a $26^{\circ} 04^{\prime} 21^{\prime \prime}$ de Latitude Sul e $53^{\circ} 11^{\prime} 28^{\prime \prime}$ de Longitude Oeste, a aproximadamente $660 \mathrm{~m}$ de altitude. É parte de uma reserva particular de $86.350 \mathrm{~m}^{2}$ de mata, limitada por áreas de pastagens e de cultivo agrícola (figura 1). O clima da região é Clima Subtropical Úmido - mesotérmico ( $\mathrm{Cfb})$, com temperatura média de $20^{\circ} \mathrm{C}$ e pluviosidade média anual de $2000 \mathrm{~mm}$ (IAPAR 1994, Klein 1970/71, Behling 1966). A litologia predominante é formada por basalto da Formação Serra Geral de idade Juro-Cretáceo. A alteração dessa rocha dá origem à formação de LATOSSOLOS, ARGISSOLOS e CAMBISSOLOS argilosos, solos enriquecidos em ferro e com relativa fertilidade natural (Nardy et al. 2002). 
Levando em consideração a pressão antrópica exercida sobre a distribuição da vegetação, o fragmento ainda mantém sua composição e densidade de espécies vegetais próximas das originais, constituindo uma fonte de informações sobre as estruturas e composição de espécies da FOM do sudoeste do Paraná.

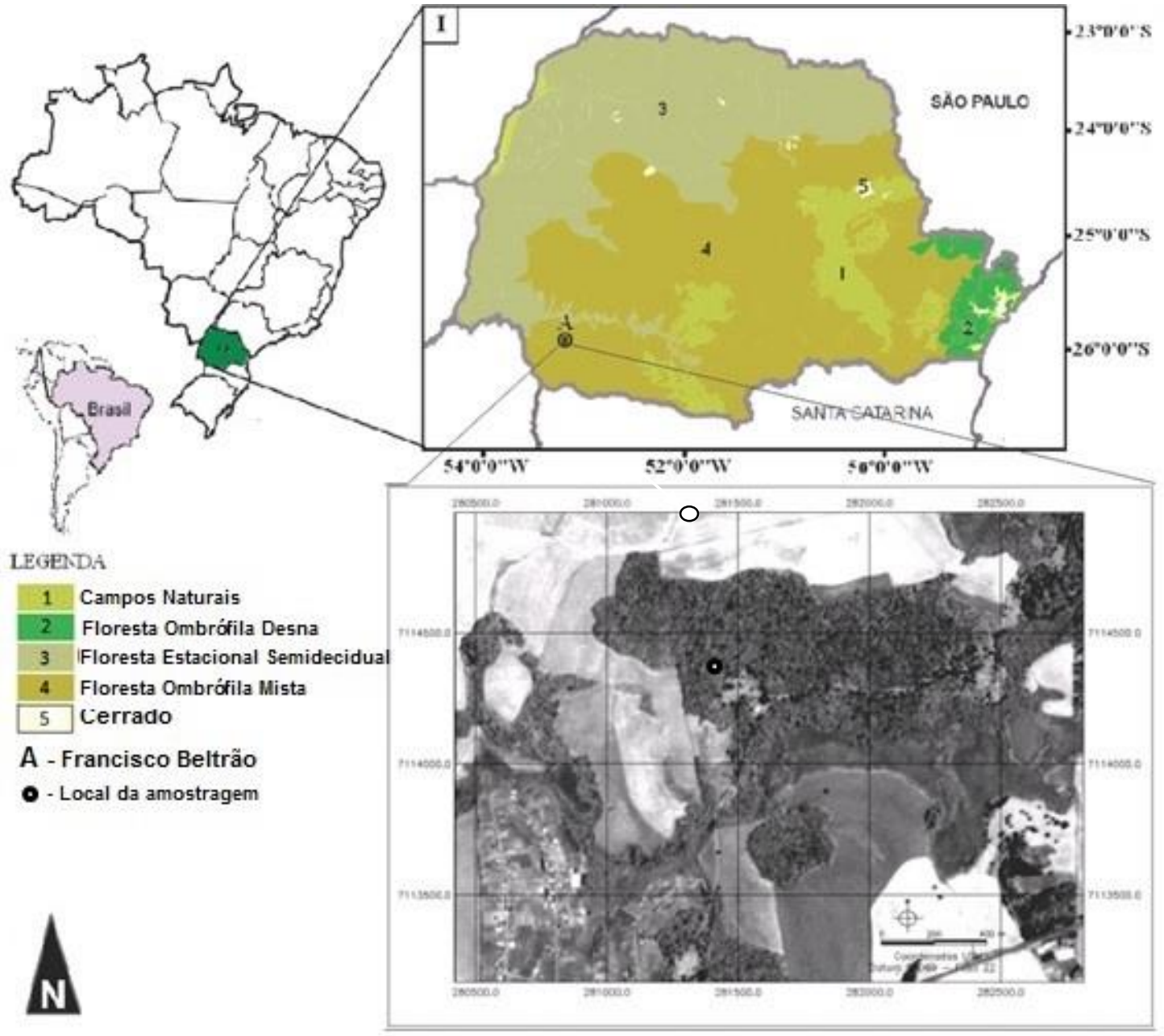

Figura 1: Localização do fragmento da Floresta Ombrófila Mista estudado. I: Mapa fitogeográfico do Estado do Paraná (ITCG 2011). A: Município de Francisco Beltrão. O ponto indicado pela seta refere-se à unidade de amostragem.

\subsection{Coleta de Plantas}

Foram coletadas 42 espécies pertencentes a 38 gêneros de 28 famílias. As espécies coletadas são as mais representativas do fragmento estudado nos diferentes estratos da vegetação (herbáceo, arbustivo e arbóreo) em termos de ocorrência no local e significado taxonômico. As coletas foram realizadas dentro de um raio de $30 \mathrm{~m}$ a partir de um ponto selecionado por ser representativo em densidade e diversidade de espécies, conforme o levantamento bibliográfico realizado. As espécies amostradas foram identificadas de acordo com o Sistema de Classificação Botânica, com auxílio da literatura botânica específica (Lorenzi \& Souza 1999, Lorenzi 2000, 2009) e por anotações das características morfológicas e distribuição das espécies em campo. Partes das amostras foram enviadas ao Museu Botânico em Curitiba (MBC) para identificação e permanecerão no Museu como resultado de pesquisa da Universidade Estadual do Oeste do Paraná - Campus Francisco Beltrão/PR (UNIOESTE/FB). As amostras foram embaladas e levadas ao laboratório de Análise e Formações Superficiais da UNIOESTE/FB para montagem das exsicatas e separação das folhas para extração de fitólitos.

Algumas espécies que não pertencer a FOM também foram amostradas, pois estavam presentes dentro do raio de amostragem. Essas espécies também são produtoras de fitólitos e estas poderiam estar preservadas na assembleia de fitólitos extraída do solo. Assim, para poder identificar esses ruídos na assinatura fitolítica desse fragmento de FOM, optou-se por manter essas espécies no trabalho. Estas espécies estão destacadas na tabela 1 . 


\subsection{Extração de fitólitos}

A extração de fitólitos foi realizada somente em folhas das espécies amostradas, seguindo os procedimentos modificados de Cavalcante (1968), Campos \& Labouriau (1969) e Piperno (2006), conhecido dry ashing. As cinzas obtidas foram montadas lâminas com Bálsamo do Canadá (coleção permanente armazenada para consulta) e em óleo de imersão (coleção temporária para identificação e descrição dos morfotipos) para cada amostra.

\subsection{Contagem e identificação de fitólitos}

A identificação, descrição e registro fotográfico das morfologias presentes nas lâminas foram realizados em microscópio óptico petrográfico Leica@ com magnificação de 630X, no Laboratório de Microscopia da UNIOESTE/FB. Uma primeira contagem foi realizada para estimar a produção relativa de fitólitos por amostra. Partindo de um peso conhecido de uma alíquota do material residual recolhido após a extração, foram contados todos os morfotipos presentes ao longo de três linhas horizontais em cada lâmina permanente. A frequência de fitólitos em cada lâmina, que permite inferir a produção fitolítica por espécie, foi classificada como: rara $(<10$ morfotipos), pouca $(10-100$ morfotipos), média (100 - 300 morfotipos) e abundante (> 300 morfotipos).

Para identificação e descrição das formas produzidas por cada espécie foram contados no mínimo 200 fitólitos com significado taxonômico por lâmina, quando possível, conforme Carnelli et al. (2002). Os morfotipos foram nomeados segundo o International Code for Phytolith Nomenclature - ICPN 1.0 (Madella et al. 2005) e agrupados de acordo com significado taxonômico de cada grupo: Mulholland (1989), Twiss (1987), Fredlund \& Tieszen (1994), Alexandre et al. (1997, 1999), Runge (1999) e Parr \& Watson (2007).

\subsection{Análise estatística}

Utilizou-se o programa MINITAB 15, versão 2011. A partir da proporção relativa $(\%)$ de cada morfotipo por amostra foram realizadas análises descritivas e, a partir de matrizes de correlação, foram realizadas as análises multivariadas de componente principal (ACP) e de agrupamento hierárquico (Cluster), empregando o método de ligação Ward (Wilton et al. 1990). Essas análises foram realizadas para a verificação do índice de dissimilaridade entre as amostras e identificação de grupos que pudessem expressar as semelhanças entre famílias e extratos da FOM.

\section{Resultados e discussões}

Foram analisadas amostras de folhas de 42 espécies pertencentes a 38 gêneros de 28 famílias, sendo uma espécie de Briófita, duas de Gimnosperma, sete espécies de Pteridófitas, oito de Monocotiledôneas, e 24 de Eudicotiledôneas (tabela 1).

De modo geral, a maioria das espécies apresentou boa produção de fitólito, à exceção das espécies $R$. gardneriana (Myrsinaceae) e A. angustifólia (Araucariaceae) em que não foram observados fitólitos, isto é, não produziram corpúsculos com formas identificáveis, maiores que $5 \mu \mathrm{m}$ de diâmetro. Nestas duas amostras observou-se apenas a formação de uma massa de Si fitogênica indefinida, cujos precipitados apresentam tamanho menor que $5 \mu \mathrm{m}$ de diâmetro sem forma definida, não sendo classificados assim como fitólitos propriamente ditos (Somer et al. 2006). Essas espécies não constam na tabela 2, onde são apresentados os morfotipos identificados e o número absoluto de frquencia de cada morfotipo por espécie.

Tabela 1: Lista de espécies amostradas e estimativa da produção de fitólitos em folhas por espécie da Floresta Ombrófila Mista (Francisco Beltrão PR).

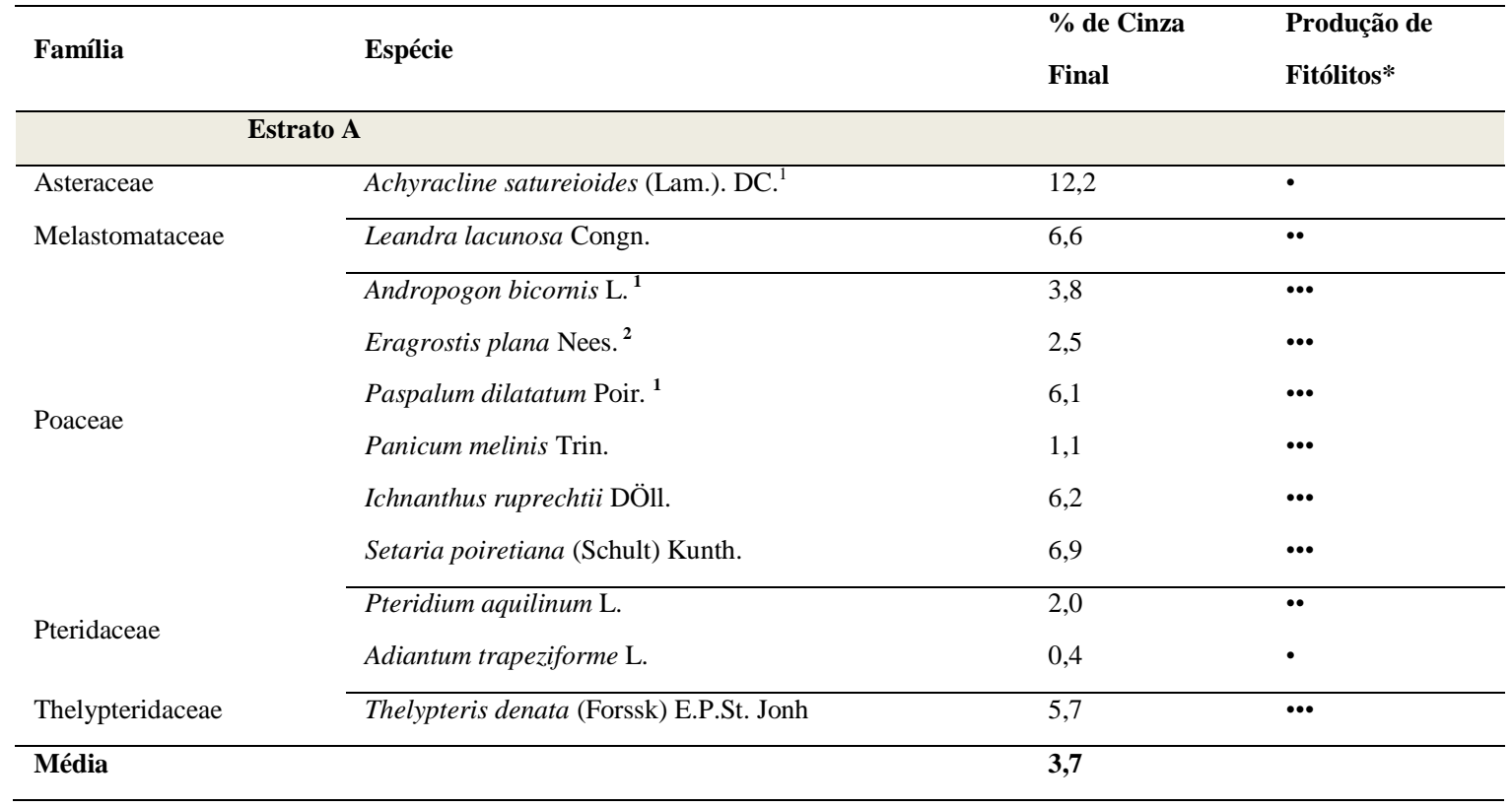


Quaternary and Environmental Geosciences (2015) 06(2):18-35

Estudos ambientais sobre a vegetação e o clima no Holoceno

\begin{tabular}{|c|c|c|c|}
\hline \multicolumn{2}{|c|}{ Estrato B } & 2,1 & $\bullet$ \\
\hline Dicksoniaceae & Dicksonia sellowiana Hook. & 1,7 & $\bullet$ \\
\hline Rubiaceae & Psychotria suterella Mull. Arg. & 2,3 & $\bullet \bullet$ \\
\hline Rutaceae & Citrus limonia Osbeck. $^{1}$ & 4,2 & - \\
\hline Piperaceae & Piper guaudichaudianum Kunth. & 7,3 & $\bullet$ \\
\hline Thelypteridaceae & Thelypteris sp. & 5,1 & $\bullet$ \\
\hline Média & & 3,6 & \\
\hline Arecaceae & Syagrus romanzoffiana (Cham). Glasman. & 6,6 & $\bullet$ \\
\hline Bignoniaceae & Handroanthus ochraceus (Cham.). Mattos. & 3,3 & $\bullet$ \\
\hline \multirow{2}{*}{ Fabaceae } & Diatenopteryx sorbifolia Radlk. & 1,3 & $\bullet$ \\
\hline & Lanchocarpus campestris Mart. Ex. Benth. ${ }^{3}$ & 2,6 & $\bullet \bullet$ \\
\hline \multirow{3}{*}{ Lauraceae } & Nectandra lanceolata Ness. & 2,9 & 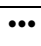 \\
\hline & Ocotea porosa Ness. & 1,6 & $\cdots$ \\
\hline & Ocotea catharinensis $\mathrm{Mez}$. & 2,1 & $\bullet$ \\
\hline Myrsinaceae & Rapanea gardneriana (A. DC) Mez. & 3,4 & + \\
\hline \multirow{2}{*}{ Salicaceae } & Prockia crucis P. Browne ex. L. & 1,4 & $\cdot$ \\
\hline & Casearia silvestris $\mathrm{Sw}$. & 1,8 & $\bullet$ \\
\hline Sapindaceae & Cupanea vernalis Cambess. & 5,2 & $\bullet$ \\
\hline Tiliaceae & Luehea divaricata Mart. & 5,1 & $\bullet$ \\
\hline Média & & 3,0 & \\
\hline
\end{tabular}

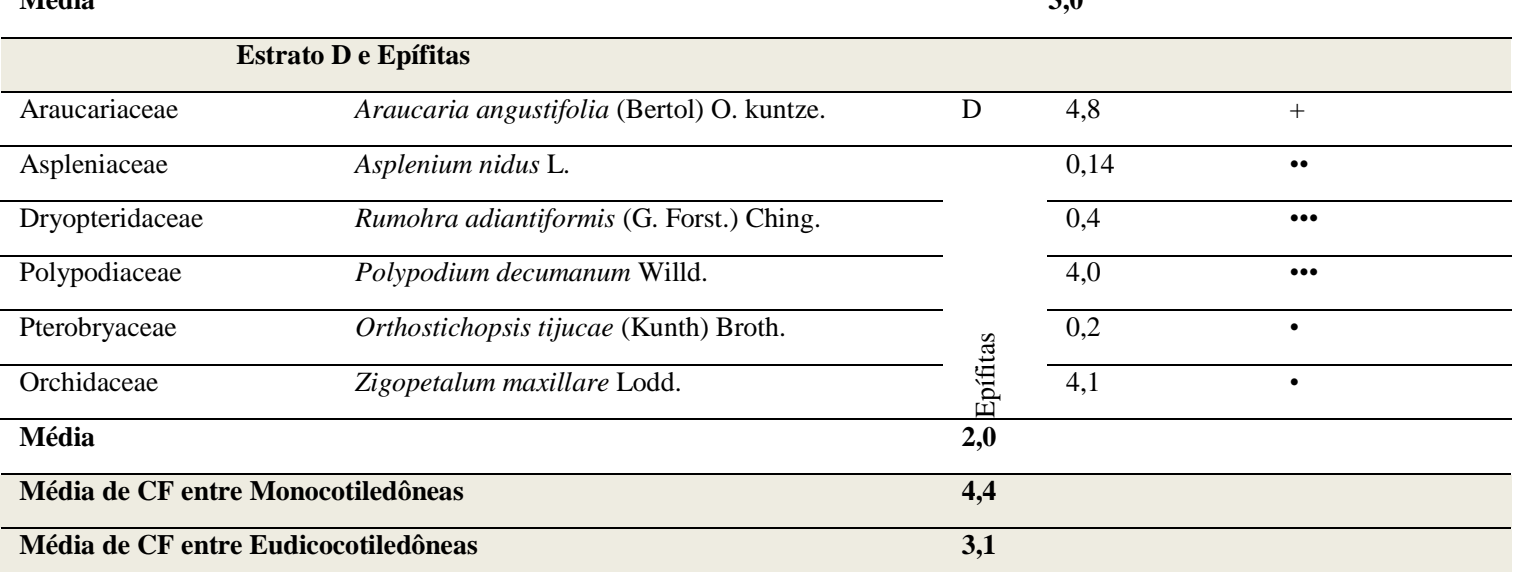

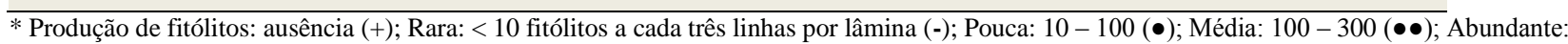
$>300(\bullet \bullet \bullet)$.

${ }^{1}$ Espécies características de Campo Limpo, Campo de Altitude e área Antrópicas

${ }^{2}$ Espécie nativa da África

${ }^{3}$ Espécie nativa da Floresta Semidecidual 
Tabela 2: Conjunto de fitólitos identificados nos estratos da Floresta Ombrófila Mista Francisco Beltrão - PR.

\begin{tabular}{|c|c|c|c|c|c|c|c|c|c|c|c|c|c|c|c|c|c|c|c|c|c|c|c|c|c|c|c|c|c|c|c|c|c|c|c|c|c|c|c|c|}
\hline & \multicolumn{11}{|c|}{ Estrato A } & \multicolumn{7}{|c|}{ Estrato B } & \multicolumn{17}{|c|}{ Estrato $\mathrm{C}$} & \multicolumn{5}{|c|}{ Estrato D e Epífitas } \\
\hline $\begin{array}{c}\text { Morfotipos } \\
\text { (ICPN 1.0) }\end{array}$ & 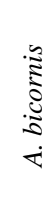 & 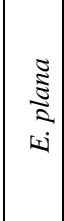 & 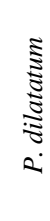 & 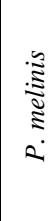 & 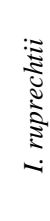 & 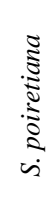 & 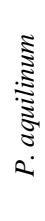 & 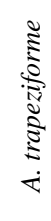 & 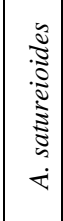 & 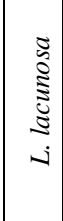 & $\begin{array}{l}\mathbb{Z} \\
\mathbb{\Xi} \\
\mathbb{Z} \\
-\end{array}$ & 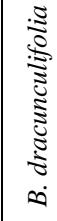 & 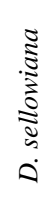 & 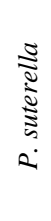 & $\begin{array}{l}\stackrel{\Xi}{\Xi} \\
\stackrel{\Xi}{\Xi} \\
ن\end{array}$ & 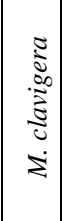 & 2 & 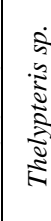 & 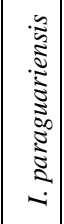 & 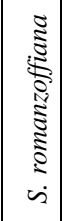 & 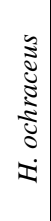 & 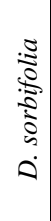 & 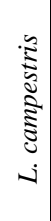 & 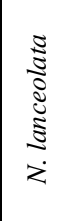 & $\begin{array}{c}5 \\
0 \\
\vdots \\
\vdots \\
0 \\
0\end{array}$ & 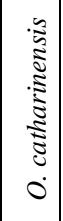 & 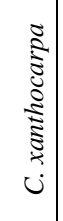 & 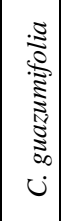 & 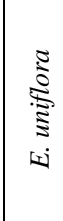 & 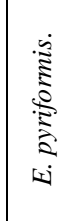 & $\underset{ن}{ن}$ & $\frac{\tilde{\sigma}}{0}$ & 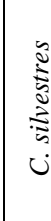 & 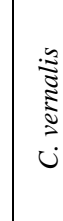 & 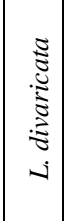 & \begin{tabular}{l}
$\mathfrak{3}$ \\
\hdashline \\
\hdashline \\
-0
\end{tabular} & 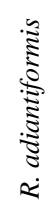 & 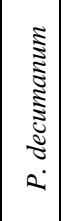 & 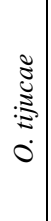 & 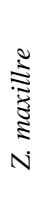 \\
\hline $\begin{array}{l}\text { Bilobate (Tipo } \\
1)^{*}\end{array}$ & 30 & 18 & 92 & 140 & 66 & 75 & - & - & - & - & - & - & - & - & - & - & - & - & - & - & - & - & - & - & - & - & - & - & - & - & - & - & - & - & - & - & - & - & - & - \\
\hline $\begin{array}{l}\text { Bilobate (Tipo } \\
2)^{*}\end{array}$ & - & 284 & 18 & - & 75 & 97 & - & - & - & - & - & - & - & - & - & - & - & - & - & - & - & - & - & - & - & - & - & - & - & - & - & - & - & - & - & - & - & - & - & - \\
\hline $\begin{array}{l}\text { Blocky } \\
\text { polygonal } \\
\text { psilate }\end{array}$ & - & - & - & - & - & 8 & - & - & - & - & - & - & - & - & - & 111 & 41 & - & 189 & - & 32 & - & 30 & 180 & 118 & 10 & - & 116 & 30 & 200 & 104 & 83 & 61 & 161 & 180 & 93 & - & - & - & - \\
\hline $\begin{array}{l}\text { Blocky } \\
\text { polygonal } \\
\text { tuberculate }\end{array}$ & - & - & - & - & - & - & - & - & - & 173 & 13 & - & - & - & 171 & - & - & - & - & - & - & - & - & - & - & - & 196 & 152 & 127 & - & - & - & - & 5 & - & - & - & - & - & - \\
\hline $\begin{array}{l}\text { Blocky } \\
\text { polygonal } \\
\text { verrucate }\end{array}$ & - & - & - & - & - & - & - & - & - & - & - & 188 & - & 60 & - & - & - & - & - & - & - & - & - & - & - & - & - & - & - & - & - & - & 12 & - & - & - & - & - & - & - \\
\hline $\begin{array}{l}\text { Clavate } \\
\text { tuberculate }\end{array}$ & - & - & - & - & - & - & - & - & - & - & - & - & - & - & - & - & - & - & - & 104 & - & - & - & - & - & - & - & - & - & - & - & - & - & - & - & - & - & - & - & - \\
\hline Cross & 11 & - & 26 & 3 & 8 & 19 & - & - & - & - & - & - & - & - & - & - & - & - & - & - & - & - & - & - & - & - & - & - & - & - & - & - & - & - & - & - & - & - & - & - \\
\hline $\begin{array}{l}\text { Cuneiform } \\
\text { Bulliform }\end{array}$ & - & 13 & - & 6 & 58 & - & - & 5 & - & - & - & - & - & - & - & - & 111 & - & - & - & - & - & - & - & - & - & - & - & - & - & - & - & - & - & - & - & - & - & - & - \\
\hline $\begin{array}{l}\text { Cylindric } \\
\text { sulcate } \\
\text { tracheid }\end{array}$ & 3 & 4 & 4 & - & 4 & 2 & - & - & 34 & - & 19 & - & - & 7 & - & - & 15 & - & 52 & 60 & - & 51 & 75 & - & 26 & - & - & - & - & 12 & 13 & 23 & - & - & - & - & - & - & - & 12 \\
\hline $\begin{array}{l}\text { Cylindric } \\
\text { bulbous }\end{array}$ & - & - & - & - & - & - & - & - & - & - & - & - & & - & 8 & - & - & - & - & - & - & - & - & - & - & - & - & - & - & - & - & - & - & - & - & - & - & - & - & - \\
\hline $\begin{array}{l}\text { Cylindric } \\
\text { convex }\end{array}$ & - & - & - & - & - & - & - & - & 73 & - & - & - & - & 11 & - & - & - & - & - & - & - & 43 & - & - & - & 11 & - & - & - & - & - & - & - & - & - & - & - & - & - & - \\
\hline $\begin{array}{l}\text { Cylindric } \\
\text { psilate }\end{array}$ & - & - & - & - & - & - & - & - & 53 & - & - & - & - & - & - & - & - & - & - & - & - & - & - & - & - & - & - & - & - & - & - & - & - & - & - & - & - & - & - & 16 \\
\hline Cylindric & - & - & - & - & - & - & - & - & - & - & - & - & - & - & - & - & - & 25 & 96 & - & - & - & - & - & - & - & - & - & - & - & - & - & - & - & - & - & - & - & - & - \\
\hline
\end{tabular}


Quaternary and Environmental Geosciences (2015) 06(2):18-35

Estudos ambientais sobre a vegetação e o clima no Holoceno

\begin{tabular}{|c|c|c|c|c|c|c|c|c|c|c|c|c|c|c|c|c|c|c|c|c|c|c|c|c|c|c|c|c|c|c|c|c|c|c|c|c|c|c|c|c|}
\hline scrobicilate & & & & & & & & & & & & & & & & & & & & & & & & & & & & & & & & & & & & & & & & \\
\hline $\begin{array}{l}\text { Cylindric } \\
\text { striate }\end{array}$ & & - & - & - & - & - & 5 & - & - & - & - & - & 14 & - & - & - & - & - & - & - & - & - & - & - & - & - & - & - & - & - & - & - & - & - & - & - & - & - & - & - \\
\hline $\begin{array}{l}\text { Cylindric } \\
\text { sulcate } \\
\text { tracheid } \\
\text { corniculate }\end{array}$ & - & - & - & - & - & - & - & - & - & - & - & - & - & - & - & - & - & - & - & 22 & - & - & - & - & - & - & - & - & - & - & - & - & - & - & - & - & - & - & - & - \\
\hline $\begin{array}{l}\text { Elipsoid } \\
\text { granulate }\end{array}$ & - & - & - & - & - & - & - & - & - & - & - & - & 4 & - & - & 30 & - & - & - & 25 & - & - & 21 & - & - & - & - & - & - & 9 & - & - & - & - & - & - & - & - & - & - \\
\hline $\begin{array}{l}\text { Elipsoid } \\
\text { psilate }\end{array}$ & - & - & - & - & - & - & - & 10 & - & - & - & - & - & - & - & - & - & - & - & - & - & - & - & - & - & - & - & - & - & - & 30 & 27 & 47 & - & - & 33 & 13 & - & - & - \\
\hline $\begin{array}{l}\text { Elipsoid } \\
\text { scrobiculate }\end{array}$ & - & - & - & - & - & - & - & - & - & - & 41 & - & - & - & - & - & - & - & - & - & - & 6 & - & - & 27 & 62 & - & - & - & - & - & - & - & - & - & - & - & 2 & - & - \\
\hline $\begin{array}{l}\text { Elongate } \\
\text { (Concave } \\
\text { ends) }\end{array}$ & - & - & - & - & 53 & - & - & - & - & - & - & - & - & - & - & - & - & - & - & - & - & - & - & - & - & - & - & - & - & - & - & - & - & - & - & - & - & - & - & - \\
\hline $\begin{array}{l}\text { Elongate } \\
\text { cavate }\end{array}$ & - & - & - & - & - & 14 & - & - & - & - & - & - & - & - & - & - & - & - & - & - & - & - & - & - & - & - & - & - & - & - & - & - & - & - & - & - & - & - & - & - \\
\hline $\begin{array}{l}\text { Elongate } \\
\text { psilate }\end{array}$ & 140 & 46 & 75 & 17 & 36 & 80 & 15 & - & 30 & - & 58 & - & 74 & - & - & 11 & - & 31 & - & - & - & 18 & - & - & - & - & - & 61 & - & - & - & - & - & - & - & - & - & 19 & - & - \\
\hline $\begin{array}{l}\text { Elongate } \\
\text { psilate (borda } \\
\text { papillate) }\end{array}$ & - & - & 18 & - & - & - & - & - & - & - & - & - & - & - & - & - & - & - & - & - & - & - & - & - & - & - & - & - & - & - & - & - & - & - & - & - & - & - & - & - \\
\hline $\begin{array}{l}\text { Elongate } \\
\text { tuberculate }\end{array}$ & - & - & - & - & - & - & - & - & - & 229 & - & - & - & 47 & 22 & - & - & - & - & - & - & - & - & - & - & - & - & - & - & - & - & - & - & 23 & - & - & - & - & - & - \\
\hline Favose cells & - & - & - & - & - & - & - & - & - & - & - & - & - & - & - & - & - & - & - & - & - & - & - & - & - & - & - & - & 10 & - & - & - & - & - & - & - & - & - & - & - \\
\hline
\end{tabular}


Tabela 2 (continuação): Conjunto de fitólitos identificados nos estratos da Floresta Ombrófila Mista Francisco Beltrão - PR.

\begin{tabular}{|c|c|c|c|c|c|c|c|c|c|c|c|c|c|c|c|c|c|c|c|c|c|c|c|c|c|c|c|c|c|c|c|c|c|c|c|c|c|c|c|c|c|}
\hline \multirow[b]{2}{*}{$\begin{array}{l}\text { Morfotipos } \\
\text { (ICPN 1.0) }\end{array}$} & \multicolumn{11}{|c|}{ Estrato A } & \multicolumn{7}{|c|}{ Estrato B } & \multicolumn{18}{|c|}{ Estrato C } & \multicolumn{5}{|c|}{ Estrato D e Epífitas } \\
\hline & 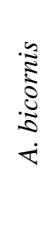 & 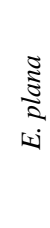 & 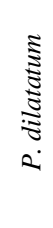 & $\begin{array}{l}\cong \\
\cong \\
\vdots \\
\vdots\end{array}$ & 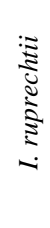 & 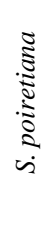 & 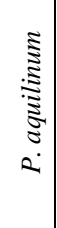 & 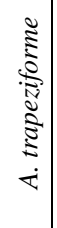 & 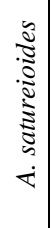 & 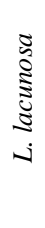 & 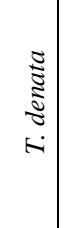 & 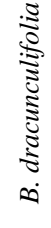 & 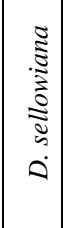 & 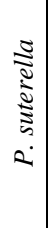 & 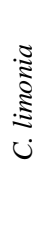 & 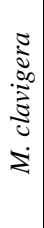 & 2 & 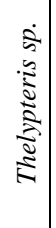 & 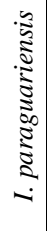 & 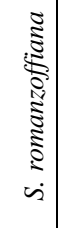 & 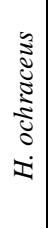 & 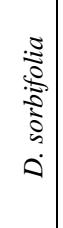 & 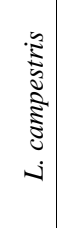 & 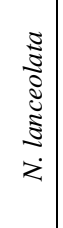 & \begin{tabular}{c|}
$\Sigma$ \\
$\vdots$ \\
$\vdots$ \\
$\vdots$ \\
$\vdots$ \\
0 \\
0
\end{tabular} & 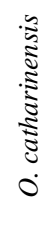 & 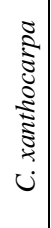 & 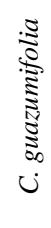 & 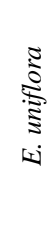 & 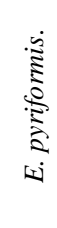 & ن & 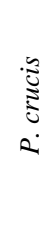 & 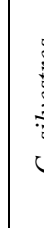 & 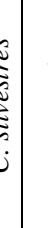 & 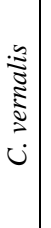 & 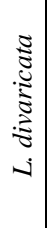 & 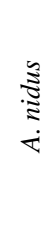 & 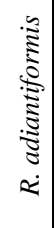 & 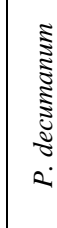 & 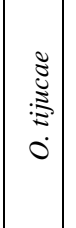 & 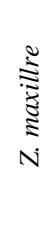 \\
\hline $\begin{array}{l}\text { Globular } \\
\text { echinate } \\
\text { smaller }<10 \\
\mathrm{~nm}\end{array}$ & - & - & - & - & - & - & - & - & - & - & - & - & - & - & - & - & - & - & - & 178 & - & - & - & - & - & - & - & - & - & - & - & - & - & & - & - & - & - & - & - & - \\
\hline $\begin{array}{l}\text { Globular } \\
\text { folded }\end{array}$ & - & - & - & - & - & - & - & 12 & - & - & - & - & - & - & - & - & - & - & - & - & - & - & - & - & - & - & - & - & - & - & - & - & - & & 9 & - & - & - & - & - & - \\
\hline $\begin{array}{l}\text { Globular } \\
\text { psilate (very } \\
\text { small } 3-5 \mu \mathrm{m})\end{array}$ & - & 87 & - & - & - & - & - & - & - & - & - & - & - & - & - & - & - & - & - & - & - & - & - & - & - & - & - & - & - & - & - & - & - & & - & - & - & - & - & - & 305 \\
\hline $\begin{array}{l}\text { Globular } \\
\text { psilate }\end{array}$ & - & - & - & - & - & - & 120 & $\begin{array}{l}5 \\
0\end{array}$ & - & - & - & - & - & - & - & - & - & - & - & 45 & - & - & - & - & 34 & - & - & - & - & - & 18 & - & 32 & & - & 18 & - & - & - & - & - \\
\hline $\begin{array}{l}\text { Globular } \\
\text { psilate larger } \\
(>10 \mu \mathrm{m})\end{array}$ & - & - & - & - & - & - & - & - & - & - & - & - & - & - & - & - & - & - & - & 45 & - & - & - & - & - & - & - & - & - & - & - & - & - & & 12 & - & - & - & - & 140 & - \\
\hline $\begin{array}{l}\text { Globular } \\
\text { verrugate } \\
\text { oblong }\end{array}$ & - & - & - & - & - & - & - & - & - & - & - & - & - & - & - & - & - & - & - & - & 66 & - & & - & 7 & - & - & - & - & - & - & - & - & & - & - & - & - & - & - & - \\
\hline $\begin{array}{l}\text { Globulares } \\
\text { echinate }>10 \\
\mathrm{~nm}\end{array}$ & - & - & - & - & - & - & - & - & - & - & - & - & - & - & - & - & - & - & - & 112 & - & - & - & - & - & - & - & - & - & - & - & - & - & & - & - & - & - & - & - & - \\
\hline Hair base & - & - & - & - & 9 & 12 & 6 & - & - & - & 39 & - & - & - & - & - & 68 & - & - & - & - & - & - & - & - & - & - & - & - & - & - & - & - & & - & - & - & - & - & - & - \\
\hline Hair cells & 10 & - & 4 & - & - & 52 & 78 & - & - & - & 87 & - & - & - & - & - & 61 & - & - & - & - & - & - & 4 & - & - & - & - & - & - & - & - & - & & - & - & - & - & - & - & - \\
\hline $\begin{array}{l}\text { Hair cells } \\
\text { (plane })\end{array}$ & - & - & - & - & - & - & - & - & - & - & - & - & - & - & - & - & - & - & - & - & - & 27 & 40 & - & - & - & - & - & - & - & - & - & - & & - & - & - & - & - & - & - \\
\hline $\begin{array}{l}\text { Irregular cells } \\
\text { (jigsaw) }\end{array}$ & - & - & - & - & - & - & 108 & - & - & - & 134 & - & 316 & - & - & - & - & 27 & - & - & - & 114 & 209 & - & - & - & - & - & - & - & - & - & - & & - & - & - & - & 60 & - & - \\
\hline $\begin{array}{l}\text { Irregular } \\
\text { psilate }\end{array}$ & - & - & - & - & - & - & 18 & - & - & - & - & - & - & - & - & - & - & - & 46 & - & - & - & - & - & 103 & - & - & - & - & - & - & - & - & & - & - & - & - & - & - & - \\
\hline
\end{tabular}


Quaternary and Environmental Geosciences (2015) 06(2):18-35

Estudos ambientais sobre a vegetação e o clima no Holoceno

\begin{tabular}{|c|c|c|c|c|c|c|c|c|c|c|c|c|c|c|c|c|c|c|c|c|c|c|c|c|c|c|c|c|c|c|c|c|c|c|c|c|c|c|c|c|}
\hline $\begin{array}{l}\text { Irregular } \\
\text { trapeziform } \\
\text { psilate }\end{array}$ & - & - & - & - & - & - & - & - & - & - & - & - & - & - & - & - & - & - & - & - & - & - & 20 & 98 & - & - & - & - & - & - & - & - & - & - & - & - & - & - & - & - \\
\hline $\begin{array}{l}\text { Paralellepipe } \\
\text { dall Bulliform } \\
10 \mu \mathrm{m}\end{array}$ & 28 & 6 & 90 & - & 14 & 8 & - & - & - & - & - & - & - & - & - & - & - & - & - & - & - & - & - & - & - & - & - & - & - & - & - & - & - & - & - & - & - & - & - & - \\
\hline $\begin{array}{l}\text { Polylobate } \\
\text { convex ( } 3 \\
\text { lóbulos) }\end{array}$ & 12 & - & 118 & 148 & 32 & 27 & - & - & - & - & - & - & - & - & - & - & - & - & - & - & - & - & - & - & - & - & - & - & - & - & - & - & - & - & - & - & - & - & - & - \\
\hline $\begin{array}{l}\text { Polylobate } \\
\text { convex } \\
\text { (Nodular } \\
\text { shank) }\end{array}$ & 9 & - & 64 & 66 & 19 & 14 & - & - & - & - & - & - & - & - & - & - & - & - & - & - & - & - & - & - & - & - & - & - & - & - & - & - & - & - & - & - & - & - & - & - \\
\hline $\begin{array}{l}\text { Polylobate } \\
\text { convex (vários } \\
\text { lóbulos) }\end{array}$ & - & - & 18 & 56 & 7 & 6 & - & - & - & - & - & - & - & - & - & - & - & - & - & - & - & - & - & - & - & - & - & - & - & - & - & - & - & - & - & - & - & - & - & - \\
\hline $\begin{array}{l}\text { Polylobate } \\
\text { crenate }\end{array}$ & - & 5 & - & - & - & - & - & - & - & - & - & - & - & - & - & - & - & - & - & - & - & - & - & - & - & - & - & - & - & - & - & - & - & - & - & - & - & - & - & - \\
\hline Prickle & - & 27 & 5 & 2 & 8 & 20 & - & - & - & - & - & - & - & - & - & - & - & - & - & - & - & - & - & - & - & - & - & - & - & - & - & - & - & - & - & - & - & - & - & - \\
\hline Saddle & - & 194 & 3 & - & - & - & - & - & - & - & - & - & - & - & - & - & - & - & - & - & - & - & - & - & - & - & - & - & - & - & - & - & - & - & - & - & - & - & - & - \\
\hline $\begin{array}{l}\text { Stomate } \\
\text { (estômato) }\end{array}$ & 40 & 43 & 12 & 1 & 3 & 92 & 18 & - & - & - & 30 & - & 21 & - & - & - & - & - & 20 & - & - & - & 40 & 76 & 112 & - & - & - & - & 46 & 13 & - & 38 & - & 22 & 3 & - & 27 & - & - \\
\hline
\end{tabular}

*Bilobate Tipo 1: short-shank, larger e lobules convex e côncavos ends >10 nm; Bilobate tipo 2: short-shank, thin e lobuless convex 
Quaternary and Environmental Geosciences (2015) 06(2):18-35

Estudos ambientais sobre a vegetação e o clima no Holoceno

Tabela 2: Conjunto de fitólitos identificados nos estratos da Floresta Ombrófila Mista Francisco Beltrão - PR.

\begin{tabular}{|c|c|c|c|c|c|c|c|c|c|c|c|c|c|c|c|c|c|c|c|c|c|c|c|c|c|c|c|c|c|c|c|c|c|c|c|c|c|c|c|c|}
\hline \multirow[b]{2}{*}{$\begin{array}{l}\text { Morfotipos } \\
\text { (ICPN 1.0) }\end{array}$} & \multicolumn{10}{|c|}{ Estrato A } & \multicolumn{8}{|c|}{ Estrato B } & \multicolumn{16}{|c|}{ Estrato C } & \multicolumn{6}{|c|}{ Estrato D e Epífitas } \\
\hline & 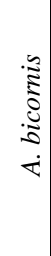 & 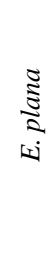 & 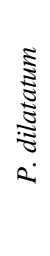 & $\begin{array}{l}\stackrel{\cong}{\Xi} \\
\stackrel{\Xi}{\Xi} \\
2\end{array}$ & 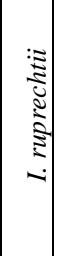 & 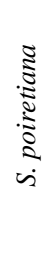 & 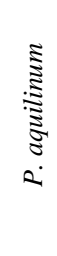 & 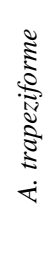 & 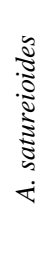 & 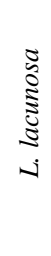 & 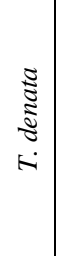 & 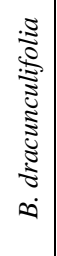 & 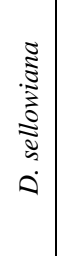 & 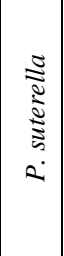 & 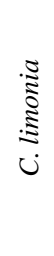 & 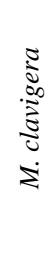 & 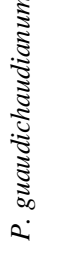 & 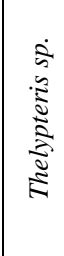 & 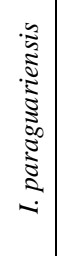 & 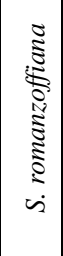 & 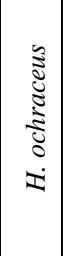 & 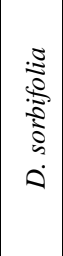 & 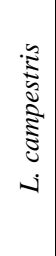 & 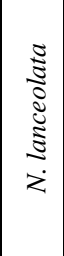 & $\begin{array}{c}\Xi \\
\vdots \\
\vdots \\
\vdots \\
\vdots \\
0\end{array}$ & 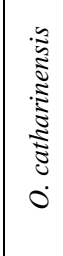 & 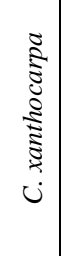 & 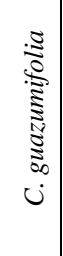 & 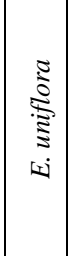 & 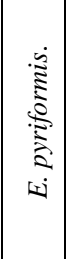 & 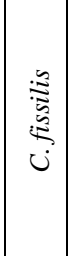 & $\begin{array}{l}0 \\
0 \\
0 \\
0 \\
0 \\
0\end{array}$ & 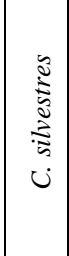 & 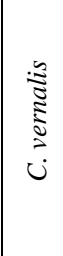 & 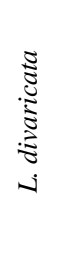 & $\begin{array}{l}\stackrel{3}{\Xi} \\
\vdots \\
+\end{array}$ & 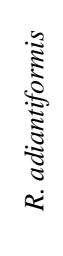 & 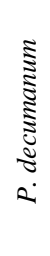 & 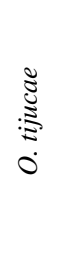 & 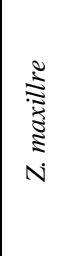 \\
\hline $\begin{array}{l}\text { Tabular } \\
\text { polygonal } \\
\text { psilate }\end{array}$ & - & - & - & - & - & - & - & - & - & - & - & - & - & - & - & - & - & - & - & - & - & 46 & - & - & 36 & - & - & - & - & 6 & - & 18 & - & 24 & - & 142 & 211 & - & - & 33 \\
\hline $\begin{array}{l}\text { Tabular } \\
\text { polygonal } \\
\text { scrobiculat } \\
e\end{array}$ & - & - & - & - & - & - & - & 6 & - & - & - & - & - & 155 & - & 25 & - & - & - & - & - & - & - & - & - & - & - & - & - & - & 78 & 77 & 74 & - & - & - & - & - & - & - \\
\hline $\begin{array}{l}\text { Tabular } \\
\text { polygonal } \\
\text { striate }\end{array}$ & - & - & - & - & - & - & - & - & - & - & - & - & - & - & - & - & - & - & - & - & - & - & - & - & - & - & - & - & - & - & - & - & - & - & - & - & - & - & - & 20 \\
\hline $\begin{array}{l}\text { Tabular } \\
\text { polygonal } \\
\text { tuberculate }\end{array}$ & - & - & - & - & - & - & - & - & - & - & - & - & - & - & - & - & - & - & - & - & - & - & - & - & - & 145 & 131 & - & - & - & - & - & - & - & 98 & - & - & - & - & - \\
\hline $\begin{array}{l}\text { Tabular } \\
\text { polygonal } \\
\text { verrucate }\end{array}$ & - & - & - & - & - & - & - & - & - & - & - & - & - & - & - & - & - & - & - & - & 98 & - & - & - & - & - & - & - & 147 & - & - & - & - & - & - & - & - & - & 40 & - \\
\hline $\begin{array}{l}\text { Trapazifor } \\
m \text { psilate }\end{array}$ & - & - & - & 75 & - & - & - & - & 8 & - & - & - & - & - & - & - & - & 133 & - & - & - & - & - & 28 & - & - & - & - & - & - & - & - & 7 & - & - & - & - & - & - & - \\
\hline $\begin{array}{r}\text { Total } \\
\text { Células } \\
\text { Simples } \\
\end{array}$ & జ్ల & $\hat{ה}$ & 点 & $\frac{7}{i n}$ & స్ & $\frac{\infty}{n}$ & 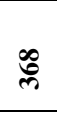 & $\infty$ & $\stackrel{2}{\vartheta}$ & ชิ & ซิ & 今ે & ఫิ & శ్ని & $\overline{\text { ন }}$ & 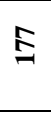 & ๙ั & $\frac{0}{\sim}$ & ชิ & 藏 & $\precsim$ & లి & 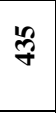 & வ & $\ddot{b}$ & జ̊ & స్ల & స్లి & $\frac{\Delta}{m}$ & $\stackrel{\overbrace{}}{\sim}$ & "ृ̊ & సి & $\underset{ה}{\mathbb{N}}$ & 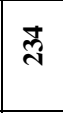 & $\frac{\infty}{m}$ & $\underset{\sim}{\mathbb{N}}$ & $\underset{\sim}{\mathbb{N}}$ & $\stackrel{\circ}{\varrho}$ & 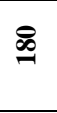 & $\underset{\infty}{\infty}$ \\
\hline $\begin{array}{l}\text { Hair cells } \\
\text { articulados }\end{array}$ & - & - & - & - & - & - & - & - & - & - & - & - & - & - & - & - & 96 & - & - & - & - & - & - & - & - & - & - & - & - & - & - & - & - & - & - & - & - & - & - & - \\
\hline $\begin{array}{l}\text { Placa } \\
\text { epidérmica }\end{array}$ & - & - & - & - & - & - & 13 & - & - & - & - & - & - & - & - & - & - & - & - & - & - & - & - & - & - & - & - & - & - & - & - & - & - & - & - & - & - & - & - & - \\
\hline $\begin{array}{r}\text { Total } \\
\text { células } \\
\text { articuladas }\end{array}$ & & & & & & & $\begin{array}{l}1 \\
3 \\
\end{array}$ & & & & & & & & & & 96 & & & & & & & & & & & & & & & & & & & & & & & \\
\hline $\begin{array}{r}\text { Total } \\
\text { Geral }\end{array}$ & 心) & $\stackrel{\widehat{N}}{\mathrm{~N}}$ & F & $\frac{7}{i n}$ & हे & $\frac{\infty}{n}$ & $\overline{\vec{\infty}}$ & $\infty$ & $\stackrel{\mathscr{\sigma}}{\sigma}$ & $\widetilde{\sigma}$ & $\ddot{\vartheta}$ & 궛 & ఫे & ๙্న & $\overline{\text { ป }}$ & $\Xi$ & लิ & $\frac{0}{N}$ & $\tilde{\xi}$ & $\overline{\text { in }}$ & $\cong$ & లి & $\mathscr{m}$ & $\infty_{\infty}^{\circ}$ & bु & $\underset{\text { స్ }}{ }$ & $\widehat{\overbrace{}}$ & స్లి & $\vec{m}$ & $\stackrel{\stackrel{N}{*}}{ }$ & "ृ. & సి & $\underset{\sim}{\mathbb{N}}$ & শ্ & $\frac{\infty}{m}$ & $\underset{\text { N }}{*}$ & $\mathbb{N}$ & $\stackrel{\infty}{\ominus}$ & $\stackrel{\mathscr{\infty}}{=}$ & $\stackrel{\circ}{\infty}$ \\
\hline
\end{tabular}

*Bilobate Tipo 1: short-shank, larger e lobules convex e côncavos ends >10 nm; Bilobate tipo 2: short-shank, thin e lobuless convex 
A A. Angustifolia apresentou produção muito baixa, classificada como rara do morfotipo globular scrobiculate. Parr \& Watson (2007) descrevem o morfotipo crater shaped como aquele de significado taxonômico para a família Araucariaceae (gêneros Araucaria e Wollemia). Entretanto, na América do Sul, o gênero Wollemia não está representado. Assim, pode-se considerar que o morfotipo crater shaped encontrado nos solos do Brasil (Calegari et al. 2013a) indica a presença de espécies pertencentes ao gênero Araucaria. Entretanto, nesta coleção o morfotipo crater shaped não foi encontrado nem nas folhas nem no lenho de amostras da A. Angustifolia, onde foi encontrado apenas o morfotipo globular scrobiculate em muito baixa frequência, por isso não apresentada na tabela 2.

A quantidade de material residual (sílica fitogênica) obtida das espécies de gramíneas é alta e a produção de fitólitos classificada como abundante (tabela 1). Tal tendência não se repete nas espécies de eudicotiledôneas, pteridófitas e briófitas que produziram quantidades de material residual relativamente elevado, porém nem sempre apresentaram boa produção de fitólitos, corroborando estudos realizados por Kealhofer \& Piperno (1998), Piperno (2006) e Bremond et al. (2008), que indicam que essas famílias apresentam baixa produtividade de fitólitos identificáveis se comparadas com a família Poaceae.

No total foram identificados 50 morfotipos diferentes entre as 40 espécies que produziram fitólitos. Foram identificados 28 morfotipos nas monocotiledôneas, 13 nas pteridófitas, 31 nas eudicotidôneas e dois nas briófitas. Assim como observado por Rovner (1971) alguns morfotipos se repetem em mais de uma família (redundância), como é o caso do elongate, tabular, estomate (estômatos), hair, block e irregular.

Considerando o menor número de espécies de monocotiledôneas em relação ao de eudicotiledôneas, observa-se que as monocotiledôneas são melhores produtoras em termos de quantidade e de diversidade de fitólitos. Exemplo é a família Poaceae, que apresentou maior diversidade de fitólitos, corroborando trabalhos realizados em outras regiões do mundo (Twiss 1992, Kealhofer \& Piperno 1998, Piperno 2006). Na figura 4 observa-se a relação entre as amostras quanto à multiplicidade e a redundância dos morfotipos produzidos pelas espécies estudadas.

A maioria das espécies apresentou morfologias diagnósticas em nível de família. As duas subfamílias de Poaceae estudadas apresentaram morfotipos com significado taxonômico já descrito por autores como Sendulsky \& Labouriau (1966), Mulholland (1989), Twiss (1987, 1992), Fredlund \& Tieszen (1994), isto é, os bilobate, polylobate e cross para as Panicoideae (figura $2, \mathrm{n}^{\text {os }} 1$ a 4 e 7 ) e o saddle para a Chloridoideae (figura 2 - 5 e 11).

As espécies pertencentes à família de Poaceae são excelentes produtoras de fitólitos (Welker \& Longhi-Wagner 2007, Berone et al. 2008, DiasMelo 2009, Veldman et al. 2009). Nesse estudo o morfotipo mais recorrente foi bilobate e suas variações, que contribuíram com 5,01\% do conjunto geral dos fitólitos produzidos pela FOM. Outros morfotipos encontrados em quantidades elevadas foram long cells - epidermal skeleto (células longas) polylobate (com variações), saddle, buliforms, prickle, cross (células curtas) (tabela 2). Os bilobates encontrados apresentam, de modo geral, hastes mais alargadas (figura 2) e lóbulos que variam entre semi-arredondados (figura 2- 1 e 10) e mais retos (figura 2- 4 e 6) típicos das Panicoideae, similares ao encontrados por Honaine et al. (2006). Também foi identificado o morfotipo em forma de cruz (cross), presente em quase todas as espécies de Chloridoideae e Panicoideae analisadas neste trabalho (tabela 2), corroborando estudos realizados com outras espécies das mesmas subfamílias (Twiss et al. 1969, Twiss 1969, 1987, 1992).

Observou-se a presença de grandes fragmentos de epiderme com várias células silicificadas, os chamados esqueletos ou articulados de sílica. Estas células epidérmicas se dispõem em fileiras longitudinais, como é característico das espécies de Poaceae (Pelegrin et al. 2009), e refletem a forte acumulação de sílica em todas as gramíneas estudadas. Além dos articulados, foram observadas outras estruturas silicificadas como parênquima paliçádico e/ou lacunoso, vasos de condução (xilema), que dão origem à forma de traqueias cilíndricas sulcadas (cylindric sulcate tracheid), e elementos subepidérmicos como os pelos (hair cell) e os prickle. Esses morfotipos foram encontrados praticamente em todas as espécies de Poaceae analisadas, com frequências variadas, à exceção da Andropogon bicornis, que não produziu os morfotipos prickle e hair cell (tabela 2). O hair não possui significado taxonômico, por serem recorrentes em várias espécies (redundância), incluindo espécies de eudicotiledôneas arbóreas (Piperno 2006). Os complexos estomáticos (stomata) não foram encontrados nas espécies Ichinantus ruprechtti e Panicum mellinis. 


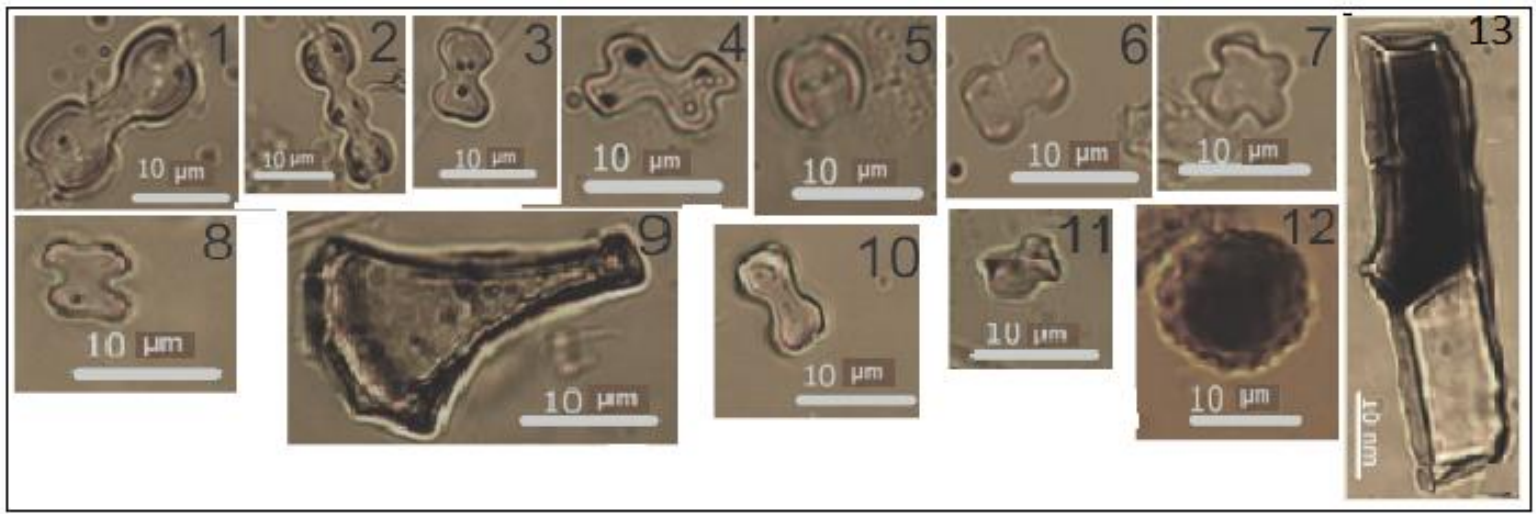

Figura 2: Morfotipos diagonósticos das subfamílias de Poaceae e família Arecaceae da FOM: 1 e 4- Bilobates short-shank long thin and lobules convex ended (A. bicornis, P. dilatatum); 2- Polylobate convex (P. mellinis); 6, 8 e 10 Bilobates short-shank larger and lobules circular ended e 7- Cross (S. poiretiana); 9- Cuneiform Bulliform (I. ruprechtii); 5 e 11- Saddle (E. plana, P. dilatatum); 12- Globular echinate (S. romanzoffiana); 13- Paralelepipedal Bulliform psilate (E. plana, P. mellinis, S. poiretiana e P. dilatatum). Barra de escala 10 $\mu$ m.

Os morfotipos em forma de paralelepípedo liso (paralelepipedal psilate), com tamanho em torno de $50 \mu \mathrm{m}$ foram identificados em amostras de Eragrostis plana, Panicum mellinis, Setaria poiretiana e Paspalum dilatatum, e os buliformes (cuneiform) somente na espécie de Ichinantus ruprechtii (figura 2 - 9).

$\mathrm{Na}$ família Aquifoliaceae a espécie $I$. paraguariensis produziu em abundância o morfotipo block polygonal (figura 3 - 20), e Cylindric scrobicilate. As formas produzidas em traqueias terminais e associações de elementos silicificados multifacetados com várias formas como irregular (figura 3-15 e 16) também foram identificadas nessa família, corroborando os estudos de Piperno (2006).

A Piperaceae, representada nessa coleção pela espécie Piper guaudichaudianum Kunth, produziu morfologias variadas, entre elas o block polygonal.
Variações do morfotipo block são comumente encontradas em eudicotiledoneae de hábito arbustivo e arbóreo (Piperno 2006), sendo interpretado no solo como indicativo da presença de uma vegetação arbórea/arbustiva (Piperno 2006, Albert et al. 2000, Madella et al. 2011).

As espécies da família Pteridaceae são reconhecidas como boas produtoras de fitólitos (Piperno 2006, Blinnikov 2005, Bozarth 1992). Nas espécies Pteridium aquilinum e Thelypteris denata foi observada elevada quantidade de morfotipos Irregular cells - jigsaw-puzzle (figura 3, 26), hair cells (figura 3, 25) e globular psilate muito pequenos (3-5 $\mu \mathrm{m})$. A espécie Adiantum trapeziform se caracteriza por apresentar elevada quantidade de globular psilate e, em menor proporção, globular folded e o elipsoid psilate (figura 3, n¹9). 
Estudos ambientais sobre a vegetação e o clima no Holoceno

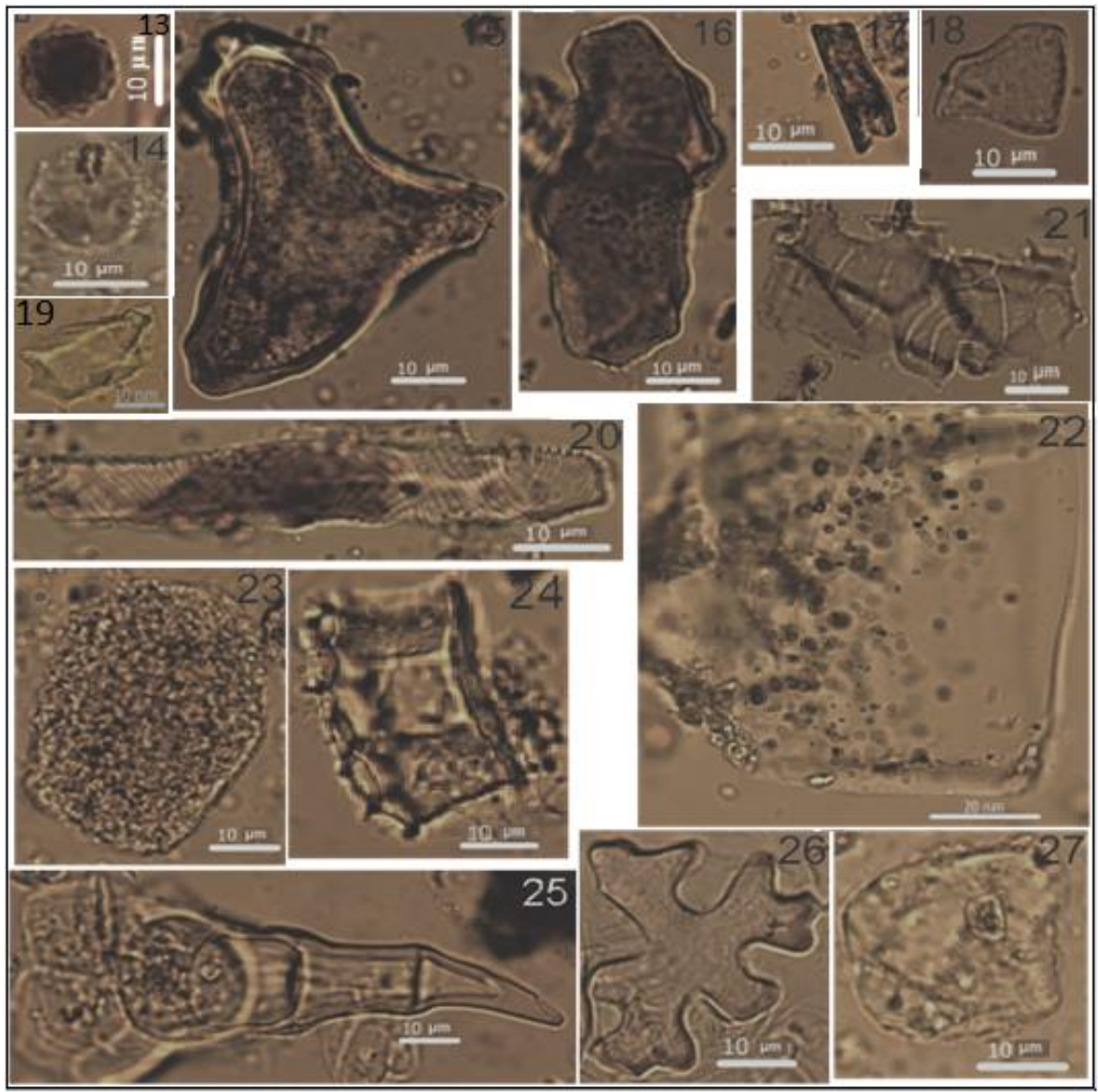

Figura 3: Morfotipos diagnósticos das famílias de eudicotiledôneas da FOM: 13 globular echinat (S. romanzoffiana); 14 Globular psilate (P. aquilinum e T. denata); 15 e 16 Irregular cells (O. porosa, N. Lanceolata); 17- Cylindric convex (A. satureioides); 18- Polygonal cells (E. pyriformis, L. divaricata); 19- Block polygonal psilate (A. trapeziformi); 20-Cylindric scrobicilate (I. paraguariensis); 21- Tabular polygonal striate (Z. maxillare); 22- Tabular polygonal psilate (R. adiantiformis, A. nidus, C. vernalis, P. crucis); 23- Tabular polygonal verrucate (E. uniflora, C. guazumifolia, C. xanthocarpa, H. ochraceus, P. suterella); 24 - Block polyedric; 25- Hair segmented (P. guaudichaudianum); 26- Irregular cells (jigsaw-puzzle) (L. campestris, D. sorbifolia, Thelypteris sp., D. sellowiana, T. denata, P. aquilinum) e 27- Blocky polygonal tuberculate (L. lacunosa, B. dracunculifolia, C. limonia, O. catharinensis, C. fissilis). Barra de escala $10 \mu \mathrm{m}$.

Os morfotipos que correspondem a silicificação de células especializadas das folhas, sejam elas da epiderme, mesoderme e/ou esclerênquima, classificados como Tabular polygonal verrucate foram muito comuns entre as eudicotiledoneas (figura 3 - 23).

Os morfotipos irregulares (jigsaw-puzzle) também são encontrados em elevada quantidade nas espécies dos gêneros da família Fabaceae dessa coleção (Diatenopterix sorbifolia e Lanchocarpus campestris). A diferença em relação aos produzidos pelas pteridófitas está no tamanho do corpúsculo, que varia de 30 a $50 \mu m$, enquanto os de pteridófitas podem chegar a $100 \mu \mathrm{m}$ no eixo longitudinal, e com menor quantidade de sinuosidades como ilustrada na figura $3\left(n^{\circ} 26\right)$.

As espécies pertencentes à família Arecaceae produzem um morfotipo diagnóstico em nível de família, o globular echinate (Albert et al. 2009). A ornamentação echinate é definida como pequenas projeções distribuídas sobre toda a superfície dos morfotipos (Piperno 2006) e foi encontrada em grande quantidade na $S$. romanzoffiana (figura 2 13).
Nas demais espécies dessa coleção a redundância foi bem marcada, como na Chyracline satureioide, que produziu os morfotipos cylindric convex psilate (figura $3, \mathrm{n}^{\mathrm{o}} 17$ ), elongate articulados e cylindric sulcate tracheid. $\mathrm{Na}$ Leandra lacunosa prevaleceram os elongate articulados e blocky polygonal tuberculate os quais aparecem nas eudicotiledôneas dessa coleção variando entre 50 a $120 \mu \mathrm{m}$.

Algumas espécies como as representantes das famílias Myrtaceae, Meliaceae, Bignoneaceae e Salicaceae aqui analisadas possuem pouca quantidade de sílica, sem produzir formas que podem classificadas sistema de nomenclatura utilizado nesta pesquisa, isto é, o ICPN 1.0 (Madella et al. 2005).

\subsection{Análise de agrupamento}

Considerando a diversidade e a quantidade de morfotipos produzidos, foi possível agrupar as espécies que apresentaram redundância nessa coleção por meio da análise de Cluster. O dendrograma (figura 4) agrupou as amostras em dois grandes grupos. O agrupamento I isolou as 
Estudos ambientais sobre a vegetação e o clima no Holoceno

Poaceae das demais famílias e demonstra baixa similaridade, que pode ser explicada, neste trabalho pelo número limitado de amostras por subfamília. Já o agrupamento II demonstrou maior grau de similaridade entre as amostras, reunindo amostras dos diferentes estratos e famílias.

No agrupamento II as espécies de eudicotiledôneas são mais similares entre si. Uma análise mais detalhada permite observar que se isolam nas extremidades desse agrupamento as espécies da família Asteraceae Achyracline satueioide (Lam). DC e Baccharis dracunculifolia, por produzirem respectivamente os morfotipos Trapeziform psilate e tabular polygonal, respectivamente.

Subgrupos podem ser observados, como o subgrupo II-I que reuniu cinco espécies (A. Satueioide, P. guaudichaudianum, Thelypteris sp, $P$. decumanum, Z. maxillare). Essas espécies apresentaram maior multiplicidade morfológica dentro do conjunto das eudicotiledôneas e as epífititas dessa coleção, não havendo correlação entre os estratos desse fragmento.

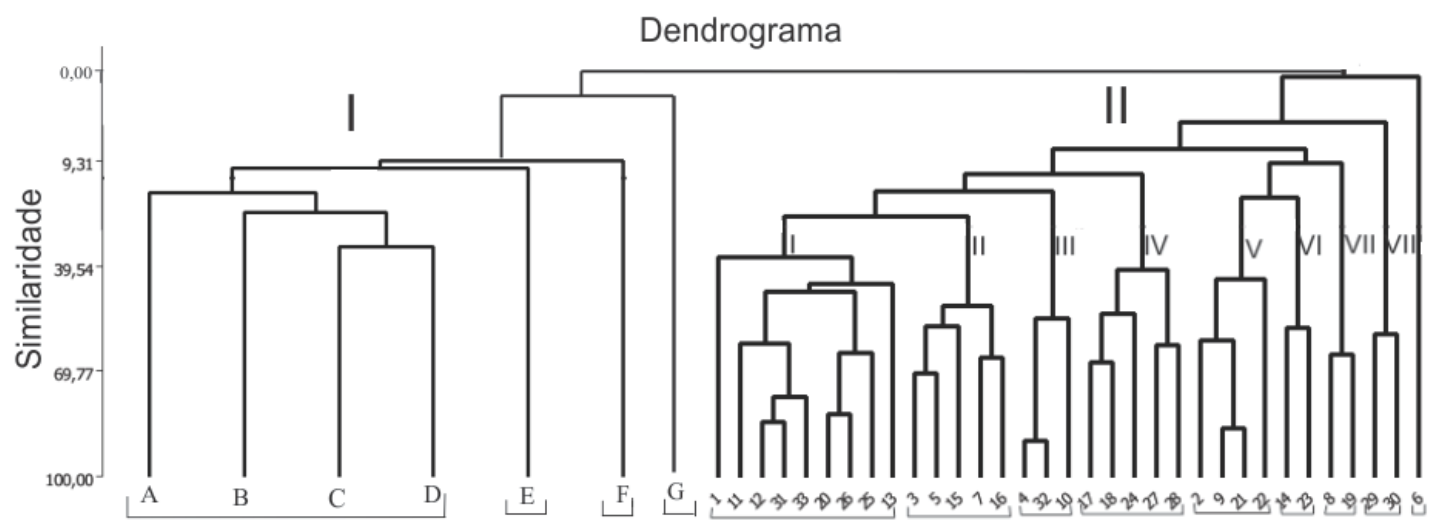

Código das espécies

\begin{tabular}{|c|c|c|c|c|c|c|c|}
\hline \multicolumn{2}{|r|}{ Estrato A } & 5 & Thelypteris denata & 13 & Ilex paraguariensis & 24 & Eugenia pyriformis \\
\hline A & Andropogon bicornis & & Estrato B & 14 & Handroanthus ochraceus & 25 & Prockia crucis \\
\hline B & Eragrostis plana & 6 & Bacckaris dracunculifolia & 15 & Diatenopteryx sorbifolia & 26 & Casearia silvestris \\
\hline $\mathrm{C}$ & Ichnanthus ruprechtii & 7 & Dicksonia sellowiana & 16 & Lanchocarpus campestris & 27 & Cupanea vernalis \\
\hline $\mathrm{D}$ & Paspalum dilatatum & 8 & Psychotria suterella & 17 & Nectandra lanceolata & 28 & Luehea divaricata \\
\hline $\mathrm{E}$ & Panicum melinis & 9 & Citrus limonia & 18 & Ocotea porosa & & Epífita \\
\hline $\mathrm{F}$ & Setaria poiretiana & 10 & Mollinedia clavigera & 19 & Ocotea catharinensis & 29 & Asplenium nidus \\
\hline 1 & Achyacline satureioides & 11 & Piper guaudichaudianum & 20 & Cedrela fissilis & 30 & Rumohra adiantiformis \\
\hline 2 & Leandra lacunosa & 12 & Thelypteris sp. & 21 & Compomanesia xanthocarpa & 31 & Polypodium decumanum \\
\hline 3 & Pteridium aquilinum & & Estrato C & 22 & Compomanesia guazumifolia & 32 & Orthostichopsis tijucae \\
\hline 4 & Adiantum trapeziforme & G & Cyagrus romanzoffiliana & 23 & Eugenia uniflora & 33 & Zigopetalum maxillare \\
\hline
\end{tabular}

Figura 4: Análise de Agrupamento Hierárquico - Método Ward - para a produção de fitólitos entre espécies de plantas amostradas em um fragmento de Floresta Ombrófila Mista - Francisco Beltrão (PR). Obs: as letras maiúsculas se referem às espécies de Poaceae.

O subagrupamento II reúne as espécies que mais produziram o morfotipo irregular cells (jigsawpuzzle): $P$. aquilinum, $T$. denata, D. sorbifolia e $L$. campestres. O subgrupo III reúne as espécies $A$. Trapeziform e $O$. tijucae e a $M$. clavigera, as que mais produziram o morfotipo cylindric sinuate. $\mathrm{O}$ subgrupo IV inclui as espécies $N$. lanceolata e $O$. porosa, mais similares entre si e a $C$. vernalis e a $L$. divaricata, que se agrupam devido à elevada produção do morfotipo polygonal cell.

Dentro do grande agrupamento II, constatou-se ainda mais três subgrupos mais parecidos entre si se comparados com os outros quatro subgrupos supradescritos. Seguindo a sequência, observou-se o subgrupo $\mathrm{V}$, que agrupa as espécies cujo morfotipo mais frequente foi o tabular polygonal
(C. limonia, C. xanthocarpa, L. lacunosa e a $C$. Guazumifolia). Os subgrupos VI, VII e VIII são formados apenas por duas amostras cada. No subgrupo VI estão as duas espécies que mais produziram o morfotipo blocky polygonal, são elas a $H$. ochraceus e a E. uniflora, no subgrupo VII estão a $P$. suterella e $O$. catharinensis, as que mais produziram o morfotipo globular oblong, reconhecido por seu significado taxonômico para eudicotiledôneas arbóreas. Finalmente, no subgrupo VIII estão as espécies $A$. nidus e a $R$. adiantiformis, plantas de hábito epífito. A amostra $B$. dracunculifolia se isola por ter sido a única espécie nessa coleção a produzir o morfotipo tabular polygonal verrucate. 
$\mathrm{Na}$ figura 5, o dendrograma representa a ordenação e similaridade entre os estratos do fragmento estudado com base no conjunto de fitólitos e a na proporção relativa de cada morfotipo em relação ao conjunto identificado em cada estrato. Observam-se dois agrupamentos bem definidos entre os estratos.

O agrupamento I o estrato A (herbáceo) se difere dos demais, onde se concentram as Poaceae e poucas espécies de Pteridaceae e eudicotiledôneas herbáceas. As Poaceae produzem uma assembleia fitolítica composta por células (bilobate, cross, saddle, trapeziform e bulliform) que não se repete em outros estratos. Também se destaca nesse estrato a elevada quantidade de morfotipos sem significado taxonômico ou ambiental (stomatas, tracheid e hair cells).

$\mathrm{O}$ estrato B (arbustivo) se diferencia do estrato C e das epífitas, porque estas últimas produzem principalmente os morfotipos globular psilate, tabular psilate Irregular cells (jigsaw-puzzle) e blocky. A quantidade de corpos de sílica (fitólitos) que se pode obter das amostras de folhas foi significativa $(>1 \%)$ em praticamente todas as espécies da FOM, indicando intensa deposição de Si nas células dessas plantas.

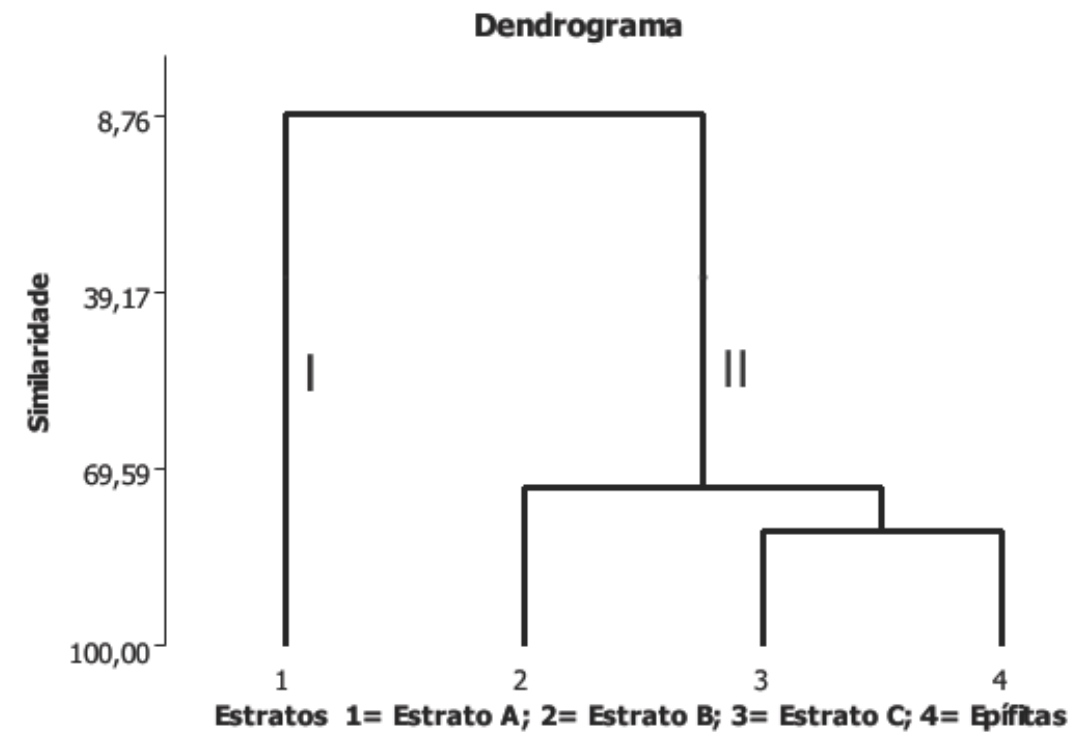

Figura 5: Análise de Agrupamento Hierárquico - Método Ward - para a produção morfológica de fitólitos entre os estratos e as epífitas da Floresta Ombrófila Mista - FOM.

A forma dos corpos silicosos não é especificamente influenciada por fatores ambientais, indicando controle genético, possuindo, portanto, considerável valor taxonômico e diagnóstico (Prychid et al. 2004). A porcentagem da produção de fitólitos com significado taxonômico foi baixa nas espécies de eudicotiledôneas. Dentre as espécies produtoras a maioria continha algum morfotipo já diagnosticado e citado na literatura para alguma espécie ou família como as Lauraceae e Fabaceae (Rovner 1971, Runge 1999, Bremond et al. 2005).

De acordo com os resultados, as espécies lenhosas são produtoras de fitólitos redundantes. Sendo assim, a importância taxonômica destes fitólitos é baixa, à exceção daqueles produzidos pelas espécies das famílias Aquifoliaceae, Lauraceae e pelas espécies de epífitas como blocky (poliédrico), cylindric, as formas globular $\mathrm{e}$ tabular, altamente silicificadas e característicos, similarmente ao observado por Mercander et al. (2009).

\section{Conclusões}

A grande diversidade de morfotipos produzidos, intra e entre famílias, pelas espécies analisadas nessa coleção reforçam a necessidade e a importância da elaboração de coleções de referências para esse tipo de vegetação. Esses aspectos também explicita a complexidade da produção de fitólitos, em termos de formas e tamanho, de cada espécie.

Em relação ao conjunto de espécies analisadas podemos considerar que:

- é forte a redundância e a multiplicidade, sobretudo entre as espécies estudadas de eudicotiledôneas;

- não foram observadas afinidades em termos de produção (quantidade e diversidade) entre os estratos;

- não foi identificado nenhum morfotipo novo de valor taxonômico em nível de espécie ou família;

- dentro do conjunto de espécies de Poaceae analisadas observou-se que existem variações morfológicas (de tamanho e número de lóbulos) dentro das categorias principais dos 
morfotipos Bilobate e Cross (gramínea C4), corroborando a literatura corrente. Essas variações podem, adicionalmente, ser consideradas nas interpretações ambiental e taxonômica no Sul do Brasil baseada na análise fitolitica.

\section{Agradecimentos}

Os autores expressam os agradecimentos ao CNPq (Proc. 472267/2009-4 e 501621/2010-5, à Fundação Araucária /SETI/Gov. Paraná (Convênio n407/2009) e ao Programa de Pós-Graduação Stricto Sensu em Geografia da Universidade Estadual do Oeste do Paraná pelo apoio financeiro. Agradecem, ainda, ao Museu Botânico de Curitiba pelo apoio na identificação de algumas espécies analisadas.

\section{Referências}

Albert R.M., Bamford M.K., Cabanes D. 2009. Palaeoecological significance of palms at Olduvai Gorge, Tanzania, based on phytolith remains. Quaternary Internacional, Oxford, 193: 41-48.

Alexandre A., Meunier J.-D. 1999. Late Holocene Phytolith and Carbon-Isotope Record from a Latosol at Salitre, SouthCentral Brazil. Quaternary Research, San Diego, 51:187194.

Alexandre A., Meunier J.D., Lczine A.-M., Vincens A., Schwartz D. A. 1997. Phytoliths: indicators of grassland dynamics during the late Holocene in intertropical Africa. Palaeogeography, Palaeoclimatology, Palaeoecology, Amsterdan, 136:213-229.

Barboni D., Bremond L., Bonnefille D. 2007. Comparative study of modern phytolith assemblages from inter-tropical Africa. Palaeogeography, Palaeoclimatology, Palaeoecology, Amsterdam, 246:454-470.

Barboni D., Bonnefille R., Alexandre A., Meunier J.D. 1999. Phytoliths as paleoenviroumental indicators, West Side Middle Awash Valley, Ethiopia. Palaeogeography, Palaeoclimatology, Palaeoecology,152:87-100.

Behling H. 1996. Late Quaternary vegetation, climate and fire history of the Araucaria Forest and campos region from Serra Campos Gerais Paraná Satate (South Brazil). Smithsonian Tropical Research Institute, P.O. Box 2072 Balboa, Panama.

Berone G.D., Lattanzi F.A., Schnyder H. 2008. Carbon gain of C3 and C4 grasses in a dense canopy in the field. Grassland Science in Europe, Vol. 15.

Blinnikov M. S. 2005. Phytolith in plants and soils of the interior Pacific Northwest, USA. Review of Paleobotany and Palynology, 135:71- 98.

Bozarth S. 1992. Classification of Opal Phytoliths Formed in Selected Dicotyledons to the Great Plains. In Rapp Jr. G, \& Mulholland, S. C. (eds.), Phytolith Systematics. Plenium Press, New York, p.113-128.

Borba-Roschel M., Alexandre A., Varajao A.F.D.C., Meunier J.D., Varajao C.A.C., Colin F. 2006. Phytoliths as indicators of pedogenesis and paleoenviro $\mu$ mental changes in Brazilian cerrado. Journal of Geochemical Exploration, Amsterdan, 88(1/3):172-176.

Bremond L., Alexandre A., Hély C., Guiot J. 2005. A phytolith index as a proxy of tree cover density in tropical areas: calibration with Leaf Area Index along a forest-savanna transect in southern Cameroon. Global and Planetary Change, 45(4): 277-293.

Bremond L., Alexandre A., Wooller M. J., Hély C., Williamson D., Schäfer P.A., Majule A., Guiot J. 2008. Phytolith indices as proxies of grass subfamilies on East African tropical mountains. Global and Planetary Change, v. 61, pp. 209224.
Brustolin L.T. 2013. Coleção de referência de fitólitos de eudicotiledôneas da Floresta Ombrófila Densa: Subsídios para reconstrução paleoambiental. Relatório Final Programa de Iniciação Científica - PRG-UNIOESTE. Universidade Estadual do Oeste do Paraná - UNIOESTE. $23 \mathrm{p}$.

Calegari M.R. 2008. Ocorrência e Significado Paleoambiental do Horizonte A Húmico em Latossolos. Tese de Doutorado, Escola Superior de Agricultura "Luiz de Queiroz"ESALQ/USP. 256 p.

Calegari M.R., Madella M., Vidal Torrado P., Pessenda L.C.R., Marques F.A. 2013. Combining phytoliths and d13C matter in Holocene palaeoenvironmental studies of tropical soils: An example of an Oxisol in Brazil. Quaternary International, 287:47-55.

Campos A.C., Labouriau L.G. 1969. Corpos silicosos de gramíneas do Cerrado - II Anais da Academia Brasileira de Ciências. Pesquisa agropecuária brasileira, 5:143-151.

Carnelli A.L., Madella M., Theurillat J.P., Ammann B. 2002. Aluminum in the opal silica reticule of phytoliths: A new tool in palaeoecological studies. Am. J. Bot., 89:346-351.

Cavalcante P.B. 1968. Contribuição ao estudo dos corpos silicosos das gramíneas amazônicas. I. Panicoideae (Melinideae, Andropogoneae e Tripsaceae), Bol. Mus. Paraense Emilio Goeldi, Botânica 30, 11 pg., 26 Est.

Cecchet F.A. 2012. Conjunto de Fitólitos dos Estratos Inferiores da Floresta Ombrófila Densa (Linhares - Espírito Santo): Subsídios para Reconstrução Paleoambiental. Marechal Cândido Rondon, PR, 82 p. Monografia (Graduação em Geografia). Universidade Estadual do Oeste do Paraná UNIOESTE

Coe H.H.G. 2009. Fitólitos como indicadores de mudanças na vegetação xeromórfica da região de Buzios/Cabo Frio, RJ, durante o Quaternário. Tese apresentada ao programa de Geologia e Geofíca Marinha, RJ, 290 p.

Coe H.H.G., Alexandre A., Carvalho C.N., Santos G.M., Silva A.S., Sousa L.O.F., Lepsch I.F. 2013. Changes in Holocene tree cover density in Cabo Frio (Rio de Janeiro, Brazil): Evidence from soil phytolith assemblages. Quaternary International, 287, pp.63-72.

Dias-Melo R., Ferreira F.M., Forzza R.C. 2009. Panicoideae (Poaceae) no Parque Estadual de Ibitipoca, Minas Gerais Brasil. Bol. Bot. Univ. São Paulo [online], 27(2):153-187. ISSN 0302-2439.

Felipe P.L.L. 2012 Coleção de Referência de Fitólitos de Eudicotiledoneae da Floresta Ombrófila Densa: Subsídios para Estudos Paleoambientais em Regiões Tropicais. Marechal Cândido Rondon, PR, 72p. Monografia (Graduação em Geografia). Universidade Estadual do Oeste do Paraná - UNIOESTE.

Figueiredo R.C.L., Handro W. 1971. Corpos silicosos de gramíneas dos Cerrados-V, 215-230p. in Ferri M.G. (ed.), III Simpósio sobre o Cerrado, 239 pg., Editora Univ. de São Paulo, Brasil.

Fredlund G.G., Tieszen L.T. 1994. Modern phytolith assemblages from the North American great plains. Journal of Biogeography, 21(3):321-335

Hodson M.J., White P.J., Mead A., Broadley M.R. 2005. Phylogenetic variation in the silicon composition in plants. Ann. Bot., 96:1027-1046

Honaine M.F., Zucol A.F., Osterrieth M.L. 2006. Phytolith Assemblages and Systematic Associations in Grassland Species of the South-Eastern Pampean Plains, Argentina. Annals of Botany, 98:1155-1165.

IAPAR - Fundação Instituto Agronômico do Paraná. 1994. Cartas climáticas básicas do Estado do Paraná. Curitiba, 49 $\mathrm{p}$.

ITCG - Instituto de Terras, Cartografia e Geociências. 2011. Disponível <http://webgeo.pr.gov.br/mapserver/itcg/geo.html> Acessado em: 14 de mar. 2011.

Kaplan L., Smith M.B., Sneddon L.A. 1992. Cereal grain phytolith of southwest Asia and Europe. In: Rapp Jr. G. Mulholland S.C. (eds.). Phytolith Systematics. Plenium Press, New York, pp. 149- 172. 
Estudos ambientais sobre a vegetação e o clima no Holoceno

Kealhofer L; Piperno D. R. 1998. Opal phytoliths in Southeast Asian flora. Smithsonian contributions to botany, n.88, 39p.

Klein R.M. 1970/1971. Fitofisionomia e Notas Complementares Sobre o Mapa Fitogeográfico de Quero-Quero (Paraná). Boletim Paranaense de Geociências- $N^{\text {os }} 28 / 29$

Kondo R., Iwasa Y. 1981. Biogenic opals of humic yellow latosols and yellow latosols in the Amazon region. Research Bulletin Obihiro University, Obihiro, 12:231-239.

Labouriau L.G., Mosquim P.R., Morhy L. 1973. Deposição de sílica nas folhas de Casearia grandiflora St. Hil., An. Acad. Brasil. Cienc. 45:545-563.

Lespch I.F., Paula L.M.A. 2006. Fitólitos em solos dos cerradões do Triângulo Mineiro: relações com atributos e silício absorvido. Caminhos de Geografia, Uberlândia, 6(19):185190.

Lorenzi H., Souza H.M. 1999. Plantas Ornamentais no Brasil: arbustivas, herbáceas e trepadeiras, 2, São Paulo, Nova Odessa, 552p.

Lorenzi H. 2000. Plantas Daninhas Do Brasil. Terrestres, Aquáticas, Parasitas e Tóxicas. Nova Odessa, São Paulo: Instituto Plantarum, $3^{\text {a }}$ edição.

Lorenzi H. 2009. Árvores Brasileiras. Manual de Identificação e Cultivo de Plantas Arbóreas Nativas do Brasil. Nova Odessa, São Paulo: Instituto Plantarum, Vol. 03, $1^{\text {a }}$ edição.

Madella M., Alexandre A., Ball T. 2005. International Code for Phytolith Nomenclature (ICPN 1.0). Annals of Botany, Oxford, 96(2):253-260.

Madella M., Carnelli A.L., Theurillat J-P., Lancelotti C. Investigando a história da vegetação (linhas de árvores) nos Alpes Centrais: Contribuições da análise de fitólitos. Espaço Plural, $N^{\circ} 25$ (2):86-93P.

Mercander J., Bennett T., Esselmont C., Simpson S., Walde D. 2009. Phytoliths in woody plants from the Miombo woodlands of Mozambique. Oxford Journals Life Sciences, Annals of Botany, $1^{\circ}$ ed.,104:91-113

Mulholland S.C. 1989. Phytolith Shape Frequencies in North Dakota Grasses: A Comparison to General Patterns. Journa of Archaeological Science, 16:489-511.

Mulholland S.C., Rapp G. Jr. 1992. Phytolith Systematics: Emerging Issues. Advances in Archaeological and Museum Science, v. 1, 350p.

Nardy A.J.R., Oliveira M.A.F., Betancurt R.H.S., Verdugo D.R.H., Machado F.B. 2002. Geologia e estratigrafia da formação Serra Geral. São Paulo, UNESP, Geociências, 21(1/2):15-32.

Osterrieth M., Martinez G., Gutierrez M., Alvarez F. 2008. Biomorfos de sílice em secuencias pedoarqueológicas del sitio Paso Otero 5. British Archaeological Research, Buenos Aires, pp. 77-90.

Osterrieth M., Madella M., Zurro D., Alvarez M.F. 2009. Taphonomical aspects of silica phytoliths in the loess sediments of the Argentinean Pampas. Quaternary International, 193:70-79.

Pelegrin C.M.G., Longhi-Wagner H.M., Oliveira P.L. 2009 Anatomia foliar como subsídio à taxonomia de espécies do Complexo Briza L (Poaceae: Pooideae:Poeae). Acta Botânica Brasileira 23 (3):666-680.

Parr J.F., Watson L. 2007. Morphological characteristics observed in the leaf phytolith of select gymnosperms of Eastern Australia. In Madella M., Zurro D. (eds). Plants, people and places: Recent Studies in phytolithic analysis, Oxbow Books, Oxford. 272p

Pearsall D.M., Chandler-Ezell K., Chandler-Ezell A. 2003. Identifying maize in neotropical sediments and soils using cob phytoliths. Journal of Archaeological Science 30 (5), 611-627

Piperno D.R. 2006. Phytoliths: A Comprehensive Guide for Archaeologists and Paleoecologists. Lanham MD, Alta Mira Press. p. 238

Piperno D.R., Pearsall D.M. 1998. The Silica Bodies of Tropical American Grasses: Morphology, Taxonomy and Implications for Grass Systematics and Fossil Phytolith Identification. Smithsonian Contributions to Botany, vol. 85

Pearsall D.M., Trimble M.K. 1984. Identifying past agricultura activity through soil phytolith analysis: a case study from the Hawaiian Islands. Jornal Archaeologic Scienci. 11, 119133.

Prychid C.J., Rudall P.J., Gregorys M. 2004. Systematics and Biology of Silica Bodies in Monocotyledons. The New York Botanical Garden. The Botanical Review, 69(4): 377440.

Raitz E. 2012. Coleção de referência de fitólitos da flora do Sudoeste do Paraná: Subsidio para estudos paleoambientais. Dissertação apresentada para a obtenção do titulo de Mestre em Geografia. Unioeste-FB, PR, 204p.

Rasbold G.G., Monteiro M.R., Parolin M., Caxambu M.G., Pessenda L.C.R. 2011. Caracterização dos tipos morfológicos de fitólitos presentes em Butia paraguayensis(Barb. Rodr.) L. H. Bailey (Arecaceae). In: Iheringia. Série Botânica v. 66, p. 265-270

Rovner I. 1971. Potential of opal phytolith for use in paleoecological reconstruction. Quaternary Research, 1:343359.

Runge F. 1999. The opal phytolith inventory of soil in central Africa - quantities, shapes, classification and spectra. Review of Palaeobotany and Palynology, Amsterdam, 107:23-53.

Sendulsky I.S., Labouriau L.G. 1966. Corpos silicosos de gramíneas dos Cerrados-I, pg. 159-170, 60 Est., In: Labouriau L.G. (edit.) II Simpósio sobre o Cerrado (An. Acad. Brasil. Cienc. 38, Supl., 346 pg.).

Sendulsky T., Labouriau L.G. 1966. Corpos silicosos de gramíneas do Cerrado - I. Anais da Academia Brasileira de Ciências. Instituto de Botânica, São Paulo - SP, 5:27

Silva S.T., Laboriau L.G. 1970. Corpos silicosos em gramíneas do cerrado III. Pesq. Agropec. Bras., v.5, p. 167-182.

Sommer M., Kaczorek D., Kuzyakov Y., Breuer J. 2006. Silicon pools and fluxes in soils and landscapes - a review. J. Plant. Nutr. Soil Science, 169, 310-239.

Söndahl M.R.I., Laboriau L.G. 1970. Corpos silicosos de gramíneas dos cerrados IV. Pesq. Agropec. Bras., 5:183207.

Strömberg C.A.E. 2007. Can slide preparation methods cause size biases in phytolith assemblages?: Results from a preliminary study. Pp. 1-12. In Madella M., Zurro D., Jones M.K. (eds). Places, People and Plants: Using Phytoliths in Archaeology and Palaeoecology. Oxbow Books.

Strömberg C.A.E. 2004. Using phytolith assemblages to reconstruct the origin and spread of grass-dominated habitats in the great plains of North America during the late Eocene to early Miocene. Palaeogeography, Palaeoclimatology, Palaeoecology, Amsterdam, 207: 239275.

Teixeira da Silva S.; Labouriau L.G. 1970. Corpos silicosos de gramíneas dos Cerrados. III, Pesq. agropec. Brasil. 5:167182

Twiss C., Suess E., Smith R.M. 1969. Morphological classification of grass phytoliths. Soil Science Society of America Proceedings, Madison, 33:109-115.

Twiss P.C. 1987. Grass opal phytoliths as climatic indicators of the Great Plains Pleistocene. In: Johnson W.C. (Ed.), Quaternary Environments of Kansas. Kansas Geological Survey Guidebook, 5:179-188

Twiss P.C. 1992. Predicted world distribution of C3 and C4 grass phytoliths. In: Rapp Jr. G.; Mulholland S.C., eds. Phytolith systematics. Emerging issues. Adv. Archaeol. Museum Sci., 1:113-128.

Veldman J.W., Mostacedo B., Peña-Claros M., Putz F.E. 2009. Selective logging and fire as drivers of alien grass invasion in a Bolivian tropical dry Forest. Forest Ecology and Management 258: 1643-1649.

Wallis L. 2003. An overview of leaf phytolith production patterns in selected Northwest Australian flora. Review of Paleobotany and Palynology, 125:201-248.

Welker C.A.D., Longhi-Wagner H.M. 2007. A família Poaceae no Morro Santana, Rio Grande do Sul, Brasil. Revista Brasileira de Biociências, Porto Alegre, 5(4):53-92.

Wilton O.B., Miaxaki É.S., Andrade D.F. 1990. Introdução à análise de agrupamentos. $9^{\circ}$ Simpósio Brasileiro de Probabilidade e Estatística. IME - USP, 93p 
Quaternary and Environmental Geosciences (2015) 06(2):18-35

Estudos ambientais sobre a vegetação e o clima no Holoceno

Zucol A.F., Brea M., Passeggi E. 2004. Estudios paleoagrostológicos comparativos em sedimentos cenozoicos argentinos. In.: F. G. Aceñolaza (Coordinador) Temas de la Biodiversidad del Litoral fluvial argentino. INSUGEO, Miscelánea, 12: 103 - 11

Recebido 06 de maio de 2014

Aceito 26 de maio de 2015 